Ministry of Education Iraqi Directorate of Education Baghdad Karkh III

وزارة التربية العراقية مديرية تربية بغداد الكرخ الثالثة

\title{
Evaluating the Content of The Second Grade Computer Book in The Light of The Skills of Knowledge Economy
}

\author{
Halah Mohammed Abed \\ Directorate of Baghdad Education Karkh III, Ministry of Education, Baghdad, Iraq
}

Halamohamed201693@yahoo.com

\begin{abstract}
This research aims at (evaluating the content of a second grade of the average year for computer book in the light of knowledge economy skills) and to achieve this the researcher adopted the descriptive approach analytical, where I prepared a list of skills of knowledge economy contents of (42) standers. The computer book was analyzed in the light of the standers, and the validity and reliability of the analysis were verified. When compared the results to the spoken, came the thinking skills in poor evaluation for all thinking skills in content of a computer book for the second grade of the average year. In light of these results, the researcher reached a set of recommendation and suggestions.
\end{abstract}

Keywords: Knowledge Economy, Content Evaluation, Computer Book.

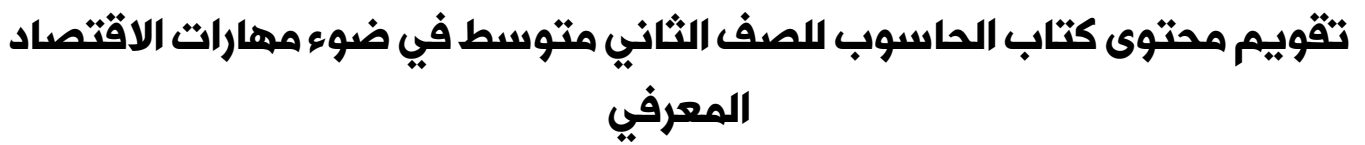

\author{
هاله محمد عبد \\ وزارة التربية، مديرية تربية بغداد الكرخ الثالثة، بغداد، العراق \\ Halamohamed201693@yahoo.com
}

المستخلص يهدف هذا البحث إلى (تقويم محتوى كتاب الحاسوب للصف الثاني متوسط في ضوء مهارات الاقتصاد المعرفي) ولتحقيقه اعتمدت الباحثة المنهج الوصفي التحليلي, حيث عدت قائمة من مهارات الاقتصاد المعرفي متكونة من (42) مؤشر وتم تحليل محتوى الكتاب في ضوئها, وتم التأكد من صدق وثبات التحليل, وعند مقارنة نتائج التحليل مع النسبة المحكية المتفق عليها من قبل المحكمين والمختصين, أظهرت النتائج حصول جميع مهارات الاقتصاد المعرفي في محتوى كتاب الحاسوب للصف الثاني متوسط على درجة تقويم ضعيف وفي ضوء تلك النتائج توصلت الباحثة الى التوصيات والمقترحات.

الكلمات الدالة:الاقتصاد المعرفي، تقويم محتوى، كتاب الحاسوب.

Abed, H. (2019). Evaluating the Content of The Second Grade Computer Book in The Light of The Skills of Knowledge Economy. Journal Port Science Research, 2(3), 509-536. doi.org/10.36371/port.2018.02.3.10 


\section{المقدمة}

أثر التقدم العلمي والتقني وثورة المعلومات في شتى مجالات الحياة الهختلفة , وكانت منظومة التربية أحدى المنظومات التي تأثرت بهذا التقدم, وبما ان التربية أساس في بناء المجتمع وتطويره، فكان التطوير لزاما' في منظومة التربية لأعداد متعلمين قادرين على الانتاج والابداع فيه وتزويدهم بمهارات حل المشكلات التي تواجههم وخاصه في عصرنا الحالي الذي يهدف الى تقليص المسافات بين الشعوب والكتل البشرية حتى نتج عن ذلك أزمات عالمية تؤثر على جميع انحاء العالم كالإرهاب وهحاربته وظهور العولمة التي اعتبرت سيف ذا حدين ويصفها البعض أنها شرا" لابد منه وأزمات محلية كالفقر والجوع والجهل. ومن هنا يأتي دور الأنظمة التربوية في تزويد الطلبة بالمعارف التي يمكن ربطها مع الواقع وامكانية تطبيقها ليتمكنوا من أنتاج المعارف الجديدة وتوظيفها في مختلف المواقف, حيث يشهد القرن الحالي (ؤية جديدة نحو (الاقتصاد المعرفي) الذي أدى الى ارتباط نظام التعليم بالاقتصاد, حيث اصبح يبنى على المعرفة ودورها في تقدم المجتمع وتطويره, فكان لابد من تطوير المناهج الدراسية واصلاحها بما يتناسب مع التقدم المتسارع في مجالي العلم والتكنلوجيا مع بقاء مناهجنا العراقية تتراوح في مكانها ولشعور الباحثة بأهمية هذا المجال الذي اوجب تضمينه في محتوى الكتب الدراسية عامة وكتاب الحاسوب خاصة, ولما لمسته من قلة البحوث والدراسات في هذا المجال ( على حد علم الباحثة ) وخبرتها المتواضعة في تدريس مادة الحاسوب لهدة عشر سنوات, وبها ان مادة الحاسوب سريعة التغيير فهي مادة ديناميكية تستثمر الامكانيات في مجالي العلم والتكنولوجيا وتسخرها في الحياة اليومية للطلبة, وتهدف الى أعداد متعلم متقبل للتطور لدية كل المهارات الاساسية واللازمة الواجب تسليحه بها, فلابد لمادة الحاسوب ان تخضع لعمليات التحليل والتقويم المستمرين بما يواكب التغييرات السريعة التي تطرأ في هذا القرن, لذا ارتأت الباحثة تقويم محتوى كتاب الحاسوب للصف الثاني المتوسط في ضوء مهارات الاقتصاد

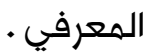 \\ • أهمية البحث}

للتربية دور كبير في نهوض المجتمع من خلال تطور البناء الاقتصادي والاجتماعي الذي يحتل الفرد فيه موقع الصدارة، وتهدف الى الاهتمام به من جميع الجوانب العقلية والسلوكية والجسمية والروحية، لأعداده علميا" واجتماعيا ونفسيا لأحداث تغييرات مرغوبة في سلوك المتعلم وفي بنيته هنه الفكرية للاستفادة من التقدم العلمي وثورة المعلومات الحاصلة في مجالي العلم والتقنية التي تشكل تحديا للمناهج، لذلك فقد اهتمت التربية بالهناهج الدراسية التي تطمح لتزويد الطلبة بالمعلومات

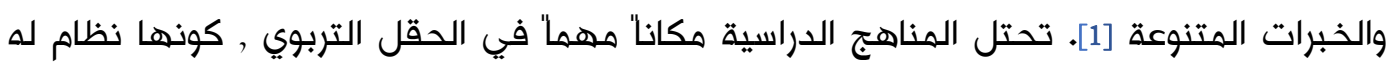
تنظيماته وأسسه, ولكي يؤدي المنهج دورة المتميز في أعداد الناشئة للحياة, يجب ان يواكب التطورات سواء كانت علمية او تقنيه التي يشهدها المجتمع , وان يكون مرنا وقابل للتعديل وفق الخطط التربوية 
التي تتوافق مع خطط الدولة في التنمية, لأن الهناهج لا تقتصر على اعداد الطلبة لمهنة معينة, انما تشهل التغيرات التي تحدثها في البنية الفكرية للمتعلمين وهذه التغيرات تؤدي الى تكوين عضو هنتج قادر على اقامة علاقات التطوير والانتاج , لذا كان لزاما على التربية ان تغير دورها لتكوين مدارس حديثة من خلال تغير الهناهج الدراسية نحو الرؤية الجديدة التي يشهدها القرن الواحد والعشرين وهي اعتماد التعليم على الاقتصاد المعرفي [2] وهن الاهداف العامة لتدريس مادة الحاسوب هو تعريف الطلبة على دور الحاسوب في سوق العمل واكتساب المهارات الاساسية التي يحتاجها لتعزز التعليم من خلال استخدام الطلبة لهذه الوسائل باحتراف داخل الهدرسة او خارجها , لبناء جيل قادر على زيادة الانتاج وتعزز روح الابداع واكسابه مهارات التفكير والاتصال وحل المشكلات تمكنه من الدخول بقوة في مجال العمل, وقد اهتمت وزارة التربية بمادة الحاسوب باعتبارها من المواد الاساسية التي تمس الحياة الواقعية للطالب وتزوده بأحدث التطورات والتغيرات في مجالي العلم والتكنلوجيا [3]. وبما ان قرن الواحد والعشرين سمي بعصر الاقتصاد المعرفي فمن المفروض ان يتضمن محتوى كتاب الحاسوب لهذا الهجال واكتساب مهاراته. حيث اعتبر من الاتجاهات الحديثة التي تنادى التربويون في تضمينه في محتوى الكتب الدراسية باعتباره المنقذ في مواجهة التحديات ويزود المتعلم بمهارات حل المشكلات وههارات التفكير العلمي وتحسين نوعية الحياة في شتى المجالات المختلفة ,فقد اصبح الاستثمار في مجالي التقنية والمعلوماتية من اهم عوامل الانتاج حيث يزيد من فرص العمل لذا تم تحول الاقتصاد القائم على راس المال والآلات والمواد الطبيعية الى اقتصاد قائم على المعرفة [4] ونتيجة هذا التحول فان نوع المهارات المطلوبة في التعليم اخذت منحنى اخر حيث اصبحت تركز على مهارات التفكير ومهارات العمل الجماعي والمهارات السلوكية وكيفية التعامل هع التكنلوجيا ومنها مهارات الاتصال , وهذا التحدي الذي يواجه الاقتصاد المعرفي وكيفية تطبيقه يتمثل في الانسجام الذي يحصل بين الهناهج الدراسية ومجال العمل وبناء علاقات قوية بين المؤسسات التعليمية وسوق العمل [5] ـ أما عملية تقويم الكتب الدراسية وتحليلها فقد حظيت لإني باهتمام كبير من قبل الباحثين، وذلك لضرورة مواكبتها للتطورات الحديثة وجعلها أكثر مرونة واستجابة للتحديات, حتى اصبحت في صميم العمل التربوي ومن اهم العمليات التي تؤثر في النظام التعليمي حيث يوفر معلومات نوعية وكمية عن المنهج الذي يتم تحليله وفق معيار معين واستخراج النتائج لتقدير مدى صلاحيته أو ملائمته لتحقيق الاهداف التربوية العامة وإصدار الاحكام في ضوء تلك النتائج ثم يتم أتخاذ القرارات المناسبة, وتعتبر عملية تقويم الكتب الدراسية العامل الذي يساعد مؤلفي الكتب على تحسين مؤلفاتهم ويساعد على أتخاذ القرارات اللازمة والصائبة من قبل الجهات المعنية في ضوء المعلومات التي يتم تقديمها عن عملية التقويم [6] • وتكمن أهمية البحث الحالي فيما يأتي: 
1) كونها أول دراسة (على حد علم الباحثة) تناولت تقويم محتوى كتاب الحاسوب وفق مهارات

$$
\text { الاقتصاد المعرفي. }
$$

2) أهمية الاقتصاد المعرفي باعتباره من الاتجاهات الحديثة الطارئة في المجال التربوي.

3) القيمة العلمية لعملية التقويم باعتباره المرحلة الاولى والاخيرة لعملية تطوير المناهج.

4) جذب انتباه وزارة التربية والتعليم لهذا النوع من الدراسات الحديثة حتى تتمكن من تقييم

$$
\text { محتوى الهناهج الدراسية وهن ثم التوصل الى قرارات مناسبة بشأنها. }
$$

تعتبر نقطة لانطلاق بحوث ودراسات أخرى تتناول مهارات الاقتصاد المعرفي في الهواد

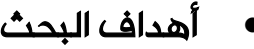

\section{يهدف البحث الحالي للإجابة عن التساؤلات التالية}

التساؤل الأول ما مهارات الاقتصاد المعرفي الواجب تضمينها في محتوى كتاب الحاسوب للصف

الثاني متوسط؟

التساؤل الثاني ما درجه تقويم محتوى كتاب الحاسوب للصف الثاني متوسط لمهارات الاقتصاد

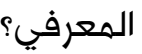

\section{• حدود البحث \\ يقتصر البحث الحالي على}

1) كتاب الحاسوب للصف الثاني متوسط المقرر من قبل وزارة التربية العراقية / ط 4/ لسنة 2014 للعام الدراسي (2019-2020) متضمن الأنشطة والأسئلة التقويمية في نهاية كل وحدة دراسية

ماعدا الصور والفهارس.

2) مهارات الاقتصاد المعرفي (المهارات الاساسية، مهارات الاتصال، مهارات التفكير، مهارات العمل الجماعي، مهارات جمع المعلومات وتنظيمها، المهارات السلوكية) ومجموعة من المؤشرات

التابعة لكل مهارة.

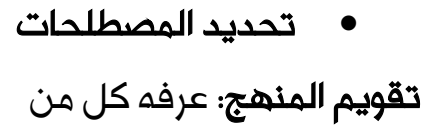

(عطية,2013) عملية يتم فيها الحصول على معلومات من خلال جمع المعلومات وتحليلها وتصنيفها ثم يتم تفسيرها وفق معيار معين لغرض تهيئتها للإصدار الاحكام واتخاذ القرارات 
(سلمان,2019) عملية منهجية ترمي الى معرفة جوانب القوة ونقاط الضعف في محتوى الكتاب المدرسي من خلال معيار أعد لهذا الغرض لإصدار الحكم القيمي علية واتخاذ القرار الهناسب حتى يتمكن من تحقيق الاهداف العامة بأحسن صورة همكنة [8]. التعريف الاجرائي للباحثة: عملية تحليل محتوى كتاب الحاسوب للصف الثاني متوسط وفق معايير مهارات الاقتصاد المعرفي لتعزيز جوانب القوة واصلاح نقاط الفشل أو المحاولة في التقليل من حدتها من خلال اصدار الحكم علية واتحاذ القرارات الصائبة. الكتاب المدرسي: عرفه كل من:

(الساموك وهدى,2009) نظام يتناول المحتوى الذي يعتبر أحد عناصر المنهج الذي يشتمل على عدة عناصر منها الاهداف والانشطة والمحتوى وطرق التدريس ويشمل جميع مفردات المحتوى الذي ينبغي

ان يتكامل عموديا وافقيا لتحقيق الاهداف التربوية، فهو المرجع الاساسي للمعلم والمتعلـم [9]. (2011, أحد عناصر المنهج يتناول عنصر المحتوى يهدف الى مساعدة المدرس في معرفة الموضوعات الرئيسة للمادة والتهيئة للدرس ويساعد الطالب في دراسته في اي صف من الصفوف ولأي مادة دراسية لتحقيق الاهداف العامة للنظام التربوي [10]. التعريف الاجرائي للباحثة محتوى كتاب الحاسوب للصف الثاني متوسط للعام الدراسي 2019 - 2020 الذي أصدرته المديرية العامة للمناج/وزارة التربية العراقية والمراد تقويمه في ضوء مهارات الاقتصاد المعرفي.

\section{مهارات الاقتصاد المعرفي: عرفها كل من}

(شفقة,2013) تتضمن مجموعة من العمليات والمعارف التي تسهم في تزويد الهتعلم بسلاح العلم وتمكنه من انتاج المعارف وليس اكتسابها فقط وبالتالي يتمكن من استخدامها في مختلف المواقف حياتية، حيث تستلزم منه استخدام مهارات التفكير وادارة المعلومات والعمل الجماعي وصنع القرارات وههارات حل المشكلات والاتصال ليتم تطويره معرفيا"ووجدانيا'وسلوكيا'[11]. (مسلم ومروان, 2017) مجموعة مهارات يجب توافرها في محتوى الكتب الدراسية التي تتطلب الحقائق والافكار والمفاهيم لتطبيق المعرفة في المواقف الواقعية المختلفة التي تواجه الطالب حيث يتوجب علية استخدام مهارات حل المشكلات والاتصال وههارات التفكير ويتم ذلك باستخدام الوسائط المتعددة في تكوين المعارف الجديدة ونشرها وتطبيقها [12]. التعريف الاجرائي للباحثة: من اهم المهارات الواجب تضمينها في محتوى كتاب الحاسوب للصف الثاني متوسط باعتباره العامل الحاسم لاكتساب الطلبة لهذه المهارات ليكونوا ذات تأثير فعال في 
في بداية القرن الواحد والعشرين واجهت المنظمات تحديات كبيرة بسبب التطورات والمتغيرات السريعة والمستمرة التي يشهدها العالم, حيث اصبح اعتمادها في رأس المال على المورد البشري ليواكب التغيرات التي أثرت على مجالات هامه مثل تكنولوجيا المعلومات والتسويق الحديث والاتصالات, فقد أولت المعرفة اهمية كبيرة بجميع انواعها سواء كانت ضمنيه أو صريحة (ظاهريه) في الحياة البشرية ليس من خلال الاستخدام فقط انما بدأ الاستثمار فيها فالمعرفة تولد معرفة جديدة من خلال خزنها واعادة سياقها ويمكن تطبيقها في كل مكان و زمان لتحقيق زيادة في عوائد تلك الهنظمات, حيث تعمل المنظمات على وضع الافكار والرؤى والنظريات لدراسة المعرفة وادارتها في مختلف التخصصات [13]. لهذا كان من الصعب وضع تعريف واحد وهحدد لمفهوم المعرفة، لأنها بناء ذات اوجه متعددة ينظر اليه من عدة مداخل وليس من السهل استيعاب تلك الأوجه والمداخل في البحث الحالي لذا نكتفي بالذكر لبعض التعاريف ومنها: عرفها (المغربي,2002): الرصيد المتكون من حصيلة البحث العلمي والدراسات الميدانية والتفكير وتطوير المشاريع الابتكارية وغيرها من مختلف اشكال الابداع الفكري للإنسان عبر الزمان [14]. ويعرفه (خلف,2007) وهي الروابط والعلاقات التي تجمع بين المعلومات وما يتم ترجمتها الى صور ذهنية من خلال التجارب والممارسات والخبرات الناجمة عنها [15]. ومن التعاريف التي ذكرت مفهوم المعرفة: مجموعه من الاحكام والمعاني والمعلوهات والتطورات الفكرية في مختلف المجالات التي يكونها الانسان نتيجة لمحاولاته المستمرة والمتكررة للتوصل الى لى لهن فهم الظواهر ومعرفة الاشياء المحيطة به [16]. ولأزاله التداخل اللفظي بين المعرفة والمعلومات فقد اشار كل من (ذياب ونجوى,2007) الى ان

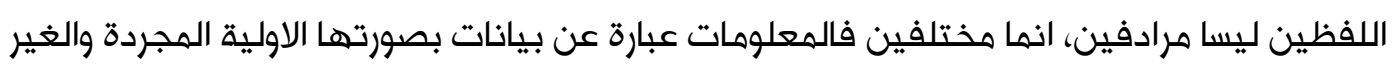
مفهومة مأخوذة عما كونته الاحداث والظواهر عبر الزمن في فكر المجتمع وتبقى البيانات خاملة حتى تصبح ذات معنى من خلال جمعها ومعالجتها ليستخدمها من يملك المعرفة. وبالتالي فقد اوضحت كلمة المعلومات على انها مجموعه من البيانات تضاف اليها معنى عند معالجتها واستخراج معانيها، وعن طريق الدراسة يمكن استخدام مهارات الملاحظة والتقصي واكتساب الفهم والوعي لاستخلاص العلاقات والمؤشرات والمقارنات بين تلك البيانات ويمكن استخدامها واستثمارها للتوصل الى نتائج مبتكرة أو تولد معرفه جديدة توسع قاعدة المعارف أو تعدل منها [17]. شكل (1) تبادل العلاقات بين البيانات والمعلومات والمعرفة [18]. 


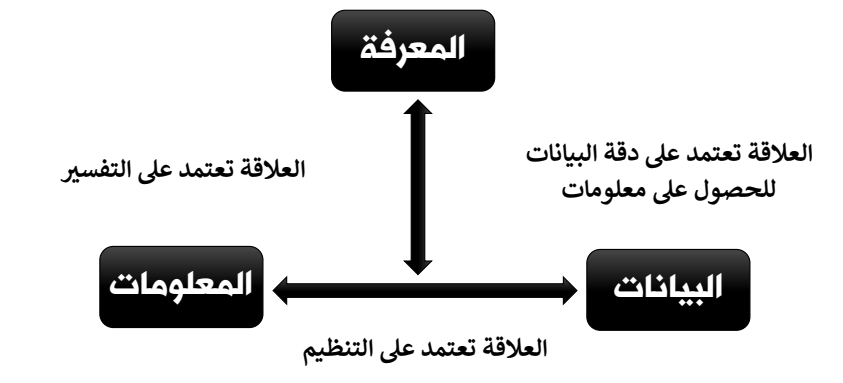

شكل رقم (1) يوضح العلاقات المتبادلة بين البيانات والمعلومات والمعرف

\section{انواع المعرفة ومراحلها \\ صنفت المعرفة الى نوعين من حيث الاكثر استخداما"وهما:}

المعرفة الضمنية: تكمن المعرفة الضمنية في عقول الافراد وفهمهم وسلوكهم اليومي فقط، فهي مخفية وهن الصعب تمثيلها أو توثيقها أو نقلها عبر تقنيات المعلومات كالحاسبات والانترنت وغيرها، الا انها توجد في حدس الافراد وقوة بصيرتهم، وفي بعض الاحيان تكون ذات طابع شخصي حيث يتم اشتقاقها بشكل ديناميكي، وتطور من خلال التفاعل الحاصل بين الخبرات العملية للأفراد

$$
\text { ومهاراتهم وادائهم في العمل [19]. }
$$

المعرفة الصريحة: تعد معرفة منظمة رسمية يمكن توثيقها وهيكلتها وتعميمها وتتضمن محتوى ثابت يمكن فهمة وادراكه كما في الوثائق والكتب، ويمكن نقلها للأخرين ومشاركتها عبر التقنيات كالحاسبات والانترنت، لذا يمكن حفظها واسترجاعها كالبيانات والمعلومات [20]. على الرغم من وجود هذا التميز بين المعرفة الضمنية والمعرفة الصريحة الا ان هناك تفاعلات مستمرة تحدث لتحويل المعرفة الضمنية الى صريحة ثم الى ضمنية بعملية لولبية تتضمن أربع مراحل: الاجتماعية،

$$
\text { والتجسيد، والضم، والدمجج. }
$$

1) الاجتماعية (Socialization): تعني تحويل المعرفة الضمنية الى معرفه ضمنية من خلال

$$
\text { التفاعل الاجتماعي ومشاركتها بين الافراد. }
$$

2) التجسيد (Externalization): في هذه المرحلة يتم تحويل المعرفة الضهنية الى معرفه صريحة وتتطلب صياغة المعرفة الضمنية وترجمتها الى صيغة يمكن ادراكها وفهمها من

$$
\text { قبل الاخرين [21]. }
$$

3) الضم (combination): تحويل المعرفة الصريحة الى مجموعات معقدة ضمن المعرفة الصريحة من خلال الترابط مع المعارف الصريحة الاخرى مثل التأليف والاندماج والتصنيف. 
ثانيا: الاقتصاد المعرفي

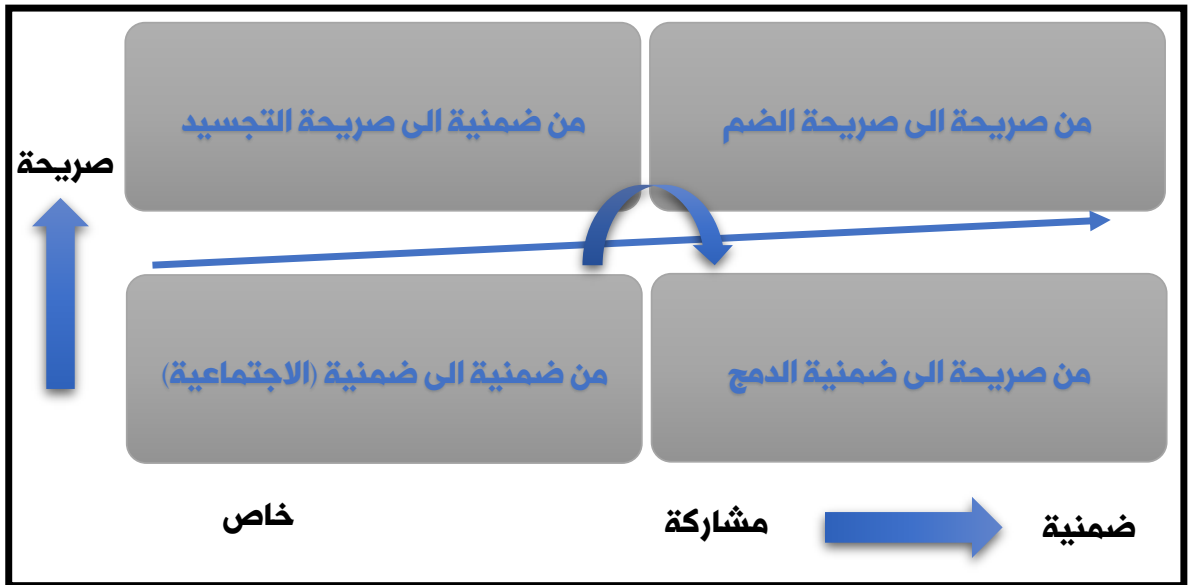

بنيت الاقتصادات الحديثة على المعرفة وتكنولوجية المعلوماتية والاتصالات, حيث ادت الى انقلاب كبير في جميع المجالات من حيث الفكر والنشاط الانساني, فلم يعد الاقتصاد يعتمد على النفط والذهب وعلى الاليات القديمة بل اصبح راس المال في عصر الاقتصاد المعرفي هو المعرفة والموارد البشرية من حيث القدرة على انتاج المعارف وتوليدها والعمل على تطبيقها والابداع فيها وصولا الى الابتكارات الحديثة، محدثة موجه سريعة وطويلة في نمو اقتصاد المجتمعات مؤدية الى تطويرها اقتصاديا ومتجهة نحو التكامل العالمي وصولا الى اقتصاد مفتوح و واعي, فقد ادى الاقتصاد المعرفي الى ظهور عدة مفاهيم جديدة منها ( المعرفة الانتاجية, والمعلوماتية, وراس المال الفكري والمورد البشري, وتفكيك التحليل). واشار (نبهان,2008) الى فوائد عديدة للاقتصاد المعرفي منها: 1) يعطي خيارات اوسع للفرد والمجتمع.

2) ينشر المعرفة ويولد معارف جديدة اخرى والعمل على تطبيقها في كل المجالات.

3) يرغم كافة المؤسسات على الابداع والتجديد في أسرع وقت ممكن. 4) استحداث وظائف جديدة أو التغير أو التعديل في الوظائف القديمة.

$$
\text { 5 ) يحقق التبادل الالكتروني. }
$$

6) يؤثر في زيادة الانتاج والمهارات المطلوبة والتوظيف والاتجاهات [23].

بناء المناهج الدراسية في عصر الاقتصاد المعرفي

في الآونة الاخيرة أصبح الاقتصاد يدور حول المعرفة وكيفية انتاجها وتطبيقها لتحسين نوعية التعليم ورفع مستوى العملية التعليمية، حيث تعد أفضل البرامج التي يتم تطبيقها على كافة 
المستويات، حيث تهدف الى جعل الطالب محور العملية التعليمية ونقله من دوره التقليدي الى دور أكثر فاعلية وايجابيه ومنتج للمعرفة في ظل التحديات العالمية الحديثة [24]. واتفق عدد من التربويين على مجموعة من الاعتبارات الواجب الاخذ بها عند بناء الهناهج الدراسية في ظل الاقتصاد

$$
\text { المعرفي وهي كالاتي: }
$$

• يجب ان تبنى المناهج بطريقه تواكب الثورة المعلوهاتية وتراعي خصائص الطالب وصفاته في

$$
\text { كل مرحلة من المراحل الدراسية. }
$$

•• يعتمد المنهج المحوري في بناء المناهج على جعل الطالب وحاجاته وميولة واتجاهاته المحور

الاساسي فيه.

$$
\text { • يجب ان يراعي الفروق الفردية بين الطلبة. }
$$

• يجب ان تكون المخرجات التعليمية في المناهج الحديثة مرغوبة وملائمة مع متطلبات المجتمع لكي تعزز قدرة الطالب ورغبته في الدراسة، ليس كمستهلك للمعرفة انما منتج لها. هُ استخدام طرائق تدريس متنوعة ومناسبة لأنماط تعلم الطلبة • تبنى المناهج على اساس اكساب الطالب للمهارات الضرورية لمواكبة متطلبات العصر. •• تلبة احتياجات الطلبة وتنمية مهاراتهم وتعزيز قدراتهم واتجاهاتهم. • ثوجه المناهج الطلبة الى مواقع وروابط الانترنت لمساعدتهم في الحصول على المعلومات بطريقة أسهل، وتعزز قدراتهم في البحث عن المعلومة. • الاهتمام بالجانب العملي والتطبيقي مضافا الى الجانب النظري، لكي يتمكن الطالب من تطبيق المعرفة في مختلف المواقف داخل المدرسة وخارجها [25].

\section{ثالثا: مهارات الاقتصاد المعرفي}

هي المهارات الضرورية التي يجب ان يكتسبها الطالب من اجل مواكبة التطورات السريعة في التقنيات الحديثة والتحديات التي يواجها الهجتمع في عصر الاقتصاد المعرفي الذي يتطلب مرونة في النظام التربوي والتعليمي من اجل التحول الى الاقتصاد المعرفي واكساب الطلبة مهاراته للتأكد من انهم قادرين على التعامل مع تطورات تكنلوجية المعرفة والاتصالات، وتدريب كافة المعلمين دون استثناء من اجل تطوير مهاراتهم وقدراتهم لمواكبة هذه التطورات ومن اجل اكمال هذا التحول يجب ان تتوافق المناهج الدراسية مع متطلبات سوق العمل [26]. ولأهمية هذه المهارات يعد تضمينها لزاما في المحتوى الدراسي من اجل اكساب الطلبة تلك الههارات التي تمكنهم من توظيفها في مختلف المواقف وتغرس فيهم العمل بروح الفريق الواحد، واتفق كل من (العمري,

$$
\text { 2004) و(الهاشمي وفائزة, 2009) على تلك الههارات وهي كالآتي: }
$$

1) المهارات الاساسية: وتتضمن القراءة والكتابة والمهارات الاساسية في تشغيل الحاسوب.

2) مهارات الاتصال: تتضمن التعبير الشفوي الحوار والاقناع والاستثارة.

Abed, H. (2019). Evaluating the Content of The Second Grade Computer Book in The Light of The Skills of Knowledge Economy. Journal Port Science Research, 2(3), 509-536. doi.org/10.36371/port.2018.02.3.10 
3) مهارات التفكير: وتشهل مهارات معرفية ومهارات غير معرفية.

4) مهارات العمل الجماعي: وتشهل التعاون مع الاخرين والعمل في فرق.

5) مهارات جمع وتنظيم المعلومات: تتضمن جمع المعلومات وتنظيمها.

6) مهارات السلوكية: وتشمل الابتكار والابداع والتجدد وتكوين فكرة والدفاع عنها وتحمل

المسؤولية [28, 27].

دراسات سابقة

دراسة ( شُفقة,2013): هدفت إلى تحليل محتوى كتب العلوم للمرحلة الاساسية العليا بغزة وفق مهارات الاقتصاد المعرفي ومدى اكتساب طلبة الصف العاشر لها واعتمد الباحث المنهج الوصفي في اعداد قائمة تتضمن مهارات الاقتصاد المعرفي مع مجموعه من المؤشرات التابعة لها, وبناء اختبار لطلبة الصف العاشر تتضمن تلك المهارات وتحقق الباحث من صدق وثبات تحليل المحتوى والاختبار وأسفرت النتائج عن تفاوت نسب مهارات الاقتصاد المعرفي في محتوى كتب العلوم للمرحلة الاساسية وبلغت نسبة اكتساب الطلبة لتلك المهارات (55.83\%) أي عدم وصولهم لحد التمكن واوصى الباحث بضرورة تطوير مناهج العلوم وفق الاتجاهات العالمية ( مهارات التفكير المنطقي). دراسة (النهراوي ,2014): هدف البحث الى تقويم جودة محتوى كتاب الرياضيات للصف الثاني ثانوي العلمي في الاردن في ضوء الاقتصاد المعرفي من وجهه نظر معلميه ولتحقيق الهدف كون الباحث استبانة تتضمن 30 فقرة تم توزيعها على خمس مجالات حصلت أربع منها على درجة تقويم (عالي الجودة) وجاء مجال المحتوى في المرتبة الاخيرة وبدرجة تقويم (متوسط الجودة) واوصى الباحث بضرورة مراجعة كتاب الرياضيات والعمل على تطويره وفق الاقتصاد المعرفي [29]. دراسة (مسلم وهروان,2017): هدف البحث إلى تحليل كتب الفيزياء للمرحلة الاعدادية في ضوء مهارات الاقتصاد المعرفي وهدى المام المدرسين بها ولتحقيقه استخدما الباحثان المنهج الوصفي التحليلي في تكوين قائمة لمهارات الاقتصاد المعرفي وتشمل مجموعة من المؤشرات وتم التأكد من لمن لهن صدق وثبات التحليل وبناء اختبار لمعرفة مدى المام مدرسي الفيزياء لهذه المهارات واظهرت النتائج ضعف تناول محتوى كتب الفيزياء لمهارات الاقتصاد المعرفي ولم يصل مستوى المامهم بها الى الحد المطلوب حيث بلغ (75\%) من درجة الاختبار الكلية.

\section{2. منهجية البحث وإجراءاته}

تحديد مجتمع البحث واختيار عينة ممثلة منه لغرض تطبيق مقياس البحث، كما يتضمن اختيار أداة البحث والوسائل الاحصائية المتبعة التي استعملت في معالجة البيانات وهي إجراءات اساسية يتبعها الباحث في تحقيق اهداف بحثه.

عبد، هاله محمد. (2019). تقويم محتوى كتاب الحاسوب للصف الثاني متوسط في ضوء مهارات الاقتصاد المعرفي. doi.org/10.36371/port.2018.02.3.10 J Journal Port Science Research 
اعتمدت الباحثة المنهج الوصفي مستخدمة اسلوب (تحليل المحتوى) في تحليل محتوى كتاب الحاسوب للصف الثاني متوسط لملائمته لطبيعة الدراسة الحالية.

\section{ثانياً: مجتمع البحث}

يمثل مجتمع البحث في جميع الوحدات الدراسية المتضمنة في محتوى كتاب الحاسوب للصف الثاني متوسط، المعتمدة من قبل وزارة التربية العراقية للعام الدراسي (2019- 2020) ويشمل الاسئلة في نهاية كل وحدة دراسية والانشطة ماعدا الفهرس والصور التوضيحية، وهو ذاته عينة البحث وقد بلغت

عدد الصفحات المحللة (160) صفحة، كما موضحة في الجدول (1). جدول (1) يوضح وحدات محتوى كثاب الحاسوب للصف الثاني متوسط

\begin{tabular}{|c|c|c|c|c|c|}
\hline عد الأسئلة & عدد الأنشطة & النسبة المئوية & عدد الصفحات & موضوع الفصل & الفصل \\
\hline 19 & 3 & $\% 42,25$ & 60 & برنامج الجداول الالكترونية & الأول \\
\hline 14 & 5 & $\% 22,54$ & 32 & شبكات الحاسوب & الثاني \\
\hline 21 & 6 & $\% 16,90$ & 24 & الانترنت & الثالث \\
\hline 21 & 0 & $\% 18,31$ & 26 & البريد الالكتروني & الرابع - - مابع \\
\hline 61 & 14 & $\% 100$ & 142 & \multicolumn{2}{|l|}{ الهجموع } \\
\hline
\end{tabular}

\section{ثالثاً: أداة البحث}

تم اعداد استبانة بصورتها الاولية لتحليل محتوى كتاب الحاسوب للصف الثاني متوسط في ضوء مهارات الاقتصاد المعرفي وفق الاجراءات التالية: - اطلاع الباحثة على مجموعة من الادبيات التربوية المتخصصة بالاقتصاد المعرفي بشكل عام وههاراته بشكل خاص. - مراجعة مجموعة من الدراسات السابقة التي لها علاقة بمهارات الاقتصاد المعرفي كدراسة (شفقة,2013)، ودراسة (مسلم ومروان,2017) وغيرها في حدود علم الباحثة. - الاخذ بآراء المحكمين والمختصين في عدة مجالات منها المناهج الدراسية وطرائق التدريس وعلم الحاسوب والقياس والتقويم. - الصورة الاولية لقائمة المهارات: تم اعداد استبانة تضمنت مهارات الاقتصاد المعرفي وفق الاجراءات التالية: إع 
تحديد المؤشرات الدالة على كل مهارة من مهارات الاقتصاد المعرفي، حيث تضمنت

القائمة ست مهارات موضحة في الجدول (2):

جدول (2) يوضح القائمة بصورتها الاولية

\begin{tabular}{|c|c|c|}
\hline عدد المؤشرات & مهارات الاقتصاد المعرفي & ت \\
\hline 13 & مهارات الاساسية & 1 \\
\hline 7 & مهارات الاتصال & 2 \\
\hline 10 & مهارات التفكير & 3 \\
\hline 4 & مهارات العمل الجماعي & 4 \\
\hline 5 & مهارات جمع وتنظيم المعلومات & 5 \\
\hline 9 & مهارات السلوكية & 6 \\
\hline
\end{tabular}

\section{رابعاً: صدق اداة البحث}

بعد عرض الاستبانة بصورتها الاولية على مجموعة من المختصين والمحكمين للتأكد من وضوح المؤشرات الدالة على المهارة، وتعديل ما يلزم سواء بالدمج أو الاضافة او الحذف او التغيير، وتم الاتفاق على نسبة (75 \%) على التعديل نسبة الى ما اشارت الية الادبيات، حيث تعتبر الفقرة صادقة [30]. اعداد استبانة (تحليل المحتوى) بصورتها النهائية: اصبحت قائمه مهارات الاقتصاد المعرفي بصورتها النهائية جاهزة ليتم من خلالها تحليل محتوى كتاب الحاسوب للصف الثاني متوسط، كما موضحه في جدول (3) جدول (3) يوضح مهارات الاقتصاد المعرفي ومؤشراتها بصورتها النهائية

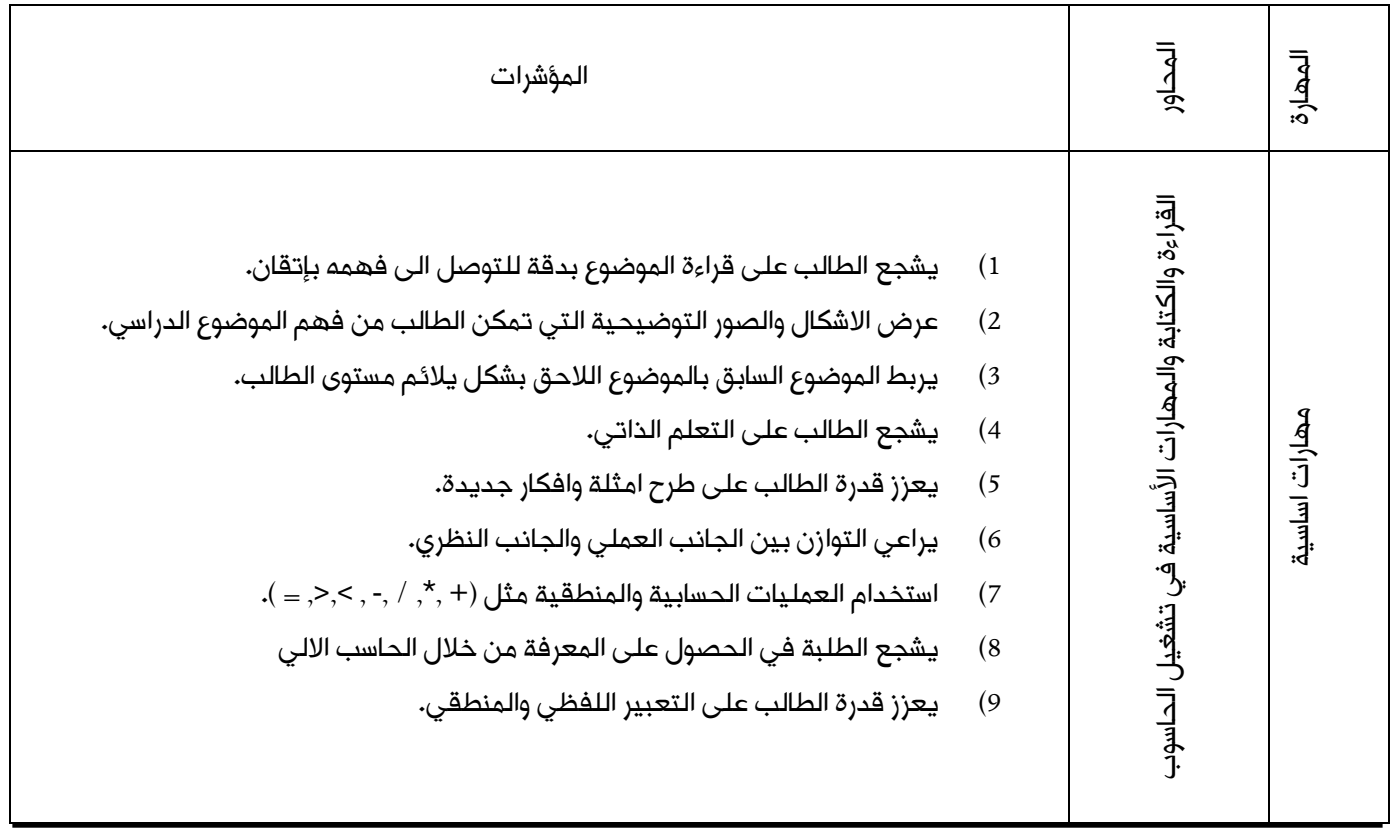

عبد، هاله محمد. (2019). تقويم محتوى كتاب الحاسوب للصف الثاني متوسط في ضوء مهارات الاقتصاد المعرفي. doi.org/10.36371/port.2018.02.3.10 J Journal Port Science Research 


\begin{tabular}{|c|c|c|}
\hline \multicolumn{3}{|c|}{ 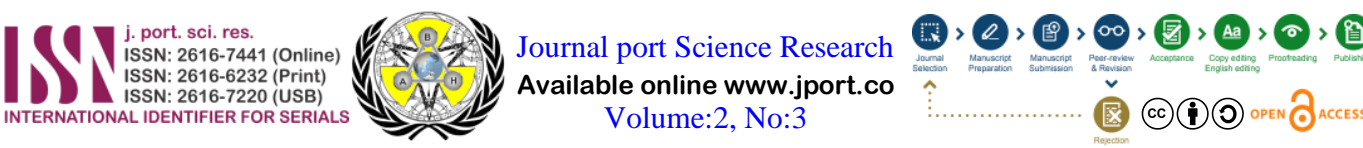 } \\
\hline 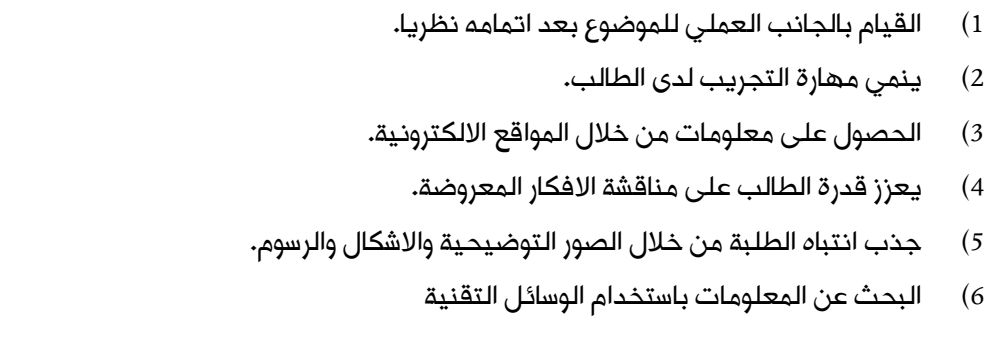 & 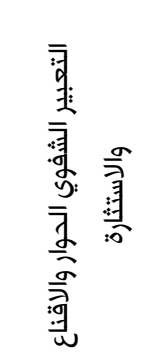 & 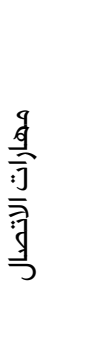 \\
\hline 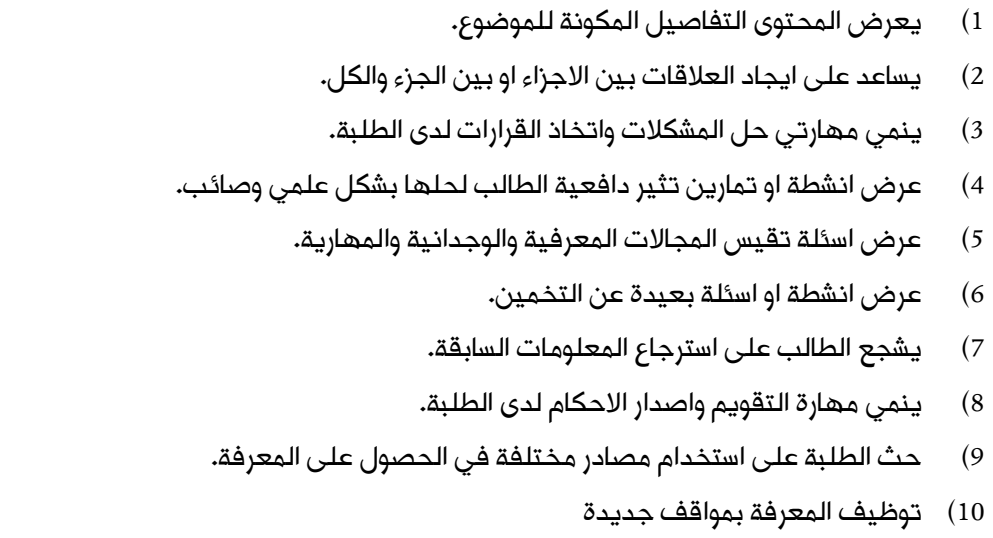 & 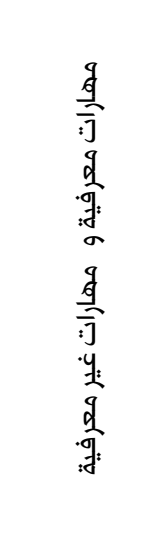 & 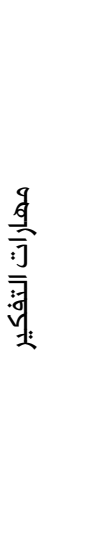 \\
\hline 3 1) & 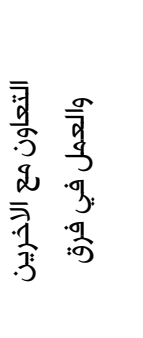 & 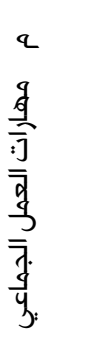 \\
\hline 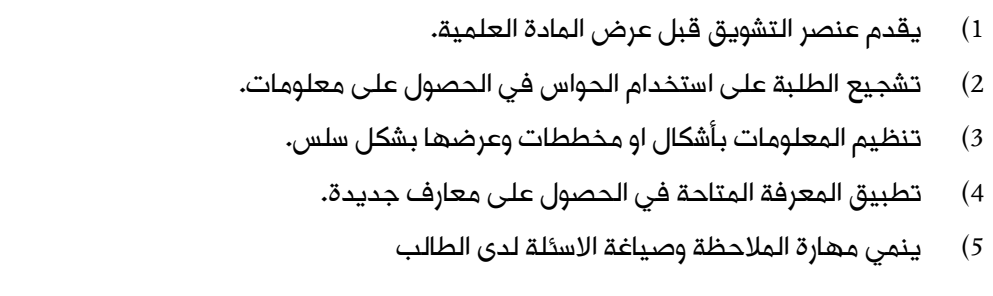 & 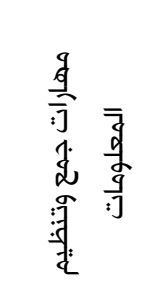 & 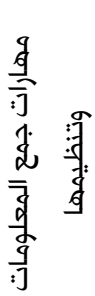 \\
\hline 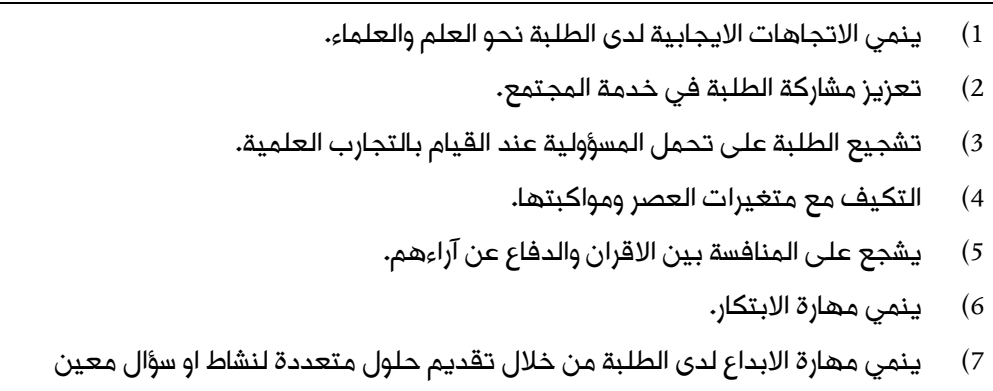 & 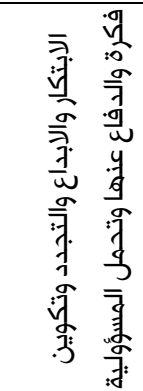 & 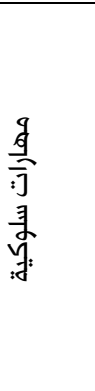 \\
\hline
\end{tabular}

Abed, H. (2019). Evaluating the Content of The Second Grade Computer Book in The Light of The Skills of Knowledge Economy. Journal Port Science Research, 2(3), 509-536. doi.org/10.36371/port.2018.02.3.10 


\section{تحديد النسبة المحكية لمهارات الاقتصاد المعرفي}

لعدم توافر النسب المحكية لهذه المهارات في الادبيات التربوية, عرضت الباحثة تلك المهارات على مجموعة من المحكمين والمختصين في عدة مجالات منها المناهج الدراسية وطرائق التدريس وعلم الحاسوب والقياس والتقويم, وطلب تحديد نسبة مثٔوية لكل مهارة من مهارات الاقتصاد المعرفي, حتى يتسنى للباحثة مقارنتها مع نتائج تحليل المحتوى, حيث تم الاتفاق على اعتبار درجة تقويم مهارات الاقتصاد المعرفي الواجب توافرها ضمن محتوى كتاب الحاسوب للصف الثاني متوسط من (90 فما فوق ) مهتاز جدا", ومن ( 80 ، 89) عالي جدا", ومن ( 70 ، 79)عالي, وهن ( 69،60) متوسط ( 59،50)

$$
\text { مقبول, ومن ( } 49 \text { فما دون) ضعيف. }
$$

اجراءات عملية التحليل

تحديد هدف التحليل: تهدف عملية تحليل المحتوى الى تحديد درجة توافر مهارات الاقتصاد

$$
\text { المعرفي في كتاب الحاسوب للصف الثاني متوسط. }
$$

تحديد عينة التحليل: تمثلت بمحتوى كتاب الحاسوب للصف الثاني متوسط المعتمدة من قبل وزارة التربية العراقية /المديرية العامة للمناهج للعام الدراسي (2019-2020). تحديد فكات التحليل: تمثلت بقائمة تحليل المحتوى بصورتها النهائية وفقا لمهارات الاقتصاد المعرفي الموضحة في الجدول (3) اعلاه. تحديد وحدة التحليل: اعتمدت الباحثة على الفكرتين الصريحة والضمنية كوحدة لتحليل المحتوى لملائمته لطبيعة الدراسة الحالية. وحدة التعداد: اعتمدت الباحثة وحدة التكرار كوحدة لتعداد ظهور الفكرة الدالة على اي مؤشر من

$$
\text { مؤشرات مهارات الاقتصاد المعرفي. }
$$

\section{ضوابط عملية التحليل: تمثلت عملية التحليل بالتالي}

- تتم عملية تحليل محتوى كتاب الحاسوب للصف الثاني متوسط ماعدا الصور التوضيحية

$$
\text { والفهرس. }
$$

- اشتملت التحليل على الانشطة والاسئلة التقويهية في نهاية كل فصل.

- اعتماد قائمة مهارات الاقتصاد المعرفي بصورتها النهائية، الموضحة في الجدول (3).

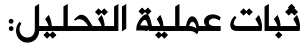

المقصود به إذا اعيد تحليل نفس محتوى الكتاب باستخدام نفس المعايير التي تم استخدامها في عملية التحليل فانة يعطي النتائج نفسها والثبات يأخذ شكلين: (1) الثبات عبر الزهن. (2) الثبات

$$
\text { هع محللين خارجين [31]. }
$$

الثبات عبر الزمن: ان يقوم المحلل بتحليل نفس المادة مرتين يفصل بينهما فترة زمنية لا تقل عن اسبوعين من دون الرجوع الى قائمة تحليل المحتوى الاولى، حيث قامت الباحثة بإعادة تحليل محتوى عبد، هاله محمد. (2019). تقويم محتوى كتاب الحاسوب للصف الثاني متوسط في ضوء مهارات الاقتصاد المعرفي. doi.org/10.36371/port.2018.02.3.10 J Journal Port Science Research 
كتاب الحاسوب للصف الثاني متوسط بعد ثلاث اسابيع من تحليلها الاولي للمحتوى، وبتطبيق معادلة جي كوبر قورنت نتائج التحليلين من خلال حساب معامل الاتفاق بينهما، حيث بلغت نسبته (85٪) وتعد ضمن النسبة المقبولة للثبات التي اشارت الكثير من الادبيات بأن نسبة الثبات تعد جيدة إذا كان مقدارها من (70\%) فما فوق [32].

الثبات مع محللين خارجين: بمعنى ضرورة توصل نتائج تحليل كل من المحللين الخارجيين الى في هن نفس نتائج تحليل الباحثة من خلال تطبيق نفس الوحدات على المضمون نفسة، وبما أن الثبات يتأثر بههارة وخبرة المحلل، لذا فقد استعانت الباحثة بمحللين من ذوي الاختصاص والخبرة* في مجال الهناهج وطرائق التدريس، وتم حساب معامل الاتفاق بين الباحثة والهحلل الأول وكانت نسبته (90\%)، وبلغ معامل الاتفاق بين الباحثة والمحلل الثاني (92\%)، لذلك يمكن الوثوق بنتائج البحث. المحلل الأول: م.م. (ينب إبراهيم حازم / تدريسية في كلية التربية ابن الهيثم، قسم علوم الحاسبات، بكالوريوس علوم حاسبات / ماجستير مناهج وطرائق تدريس عامة. المحلل الثاني: م.م. أمنه سلمان محمد علي /دائرة التعليم الديني والدراسات الإسلامية / قسم المناهج والتطوير، بكالوريوس علوم حاسبات / ماجستير مناهج وطرائق تدريس عامة. الوسائل الإحصائية Statistical Means اعتمدت الباحثة الوسائل الإحصائية التالية: 1) التكرارات والنسبة المئوية. 2) معادلة جي كوبر G-Cooper ل استخراج ثبات التحليل.

2. عرض النتائج وتفسيرها سيتم عرض نتائج هدف البحث تقويم محتوى كتاب الحاسوب للصف الثاني متوسط في ضوء مهارات الاقتصاد المعرفي وتفسيرها وفقا'للتساؤلات التالية: التساؤل الأول: ما مهارات الاقتصاد المعرفي الواجب تضمينها في محتوى كتاب الحاسوب للصف الثاني متوسط؟ عرضت الباحثة قائمة من مهارات الاقتصاد المعرفي ولكل مهارة مجموعه من المؤشرات الدالة عليها في الفصل الثالث بإجراءات البحث في الجدول (3) بصورتها النهائية، وبذلك تم الاجابة عن التساؤل الاول. التساؤل الثاني: ما درجه تقويم محتوى كتاب الحاسوب للصف الثاني متوسط لمهارات الاقتصاد

وللإجابة عن التساؤل الثاني قامت الباحثة بتحليل محتوى كتاب الحاسوب للصف الثاني متوسط وفق قائمة لمهارات الاقتصاد المعرفي والتي تتضمن مجموعه من المؤشرات الخاصة بكل مهارة، وتم 
حساب تكراراتها والنسبة المئوية لتضمين كل مهارة من مهارات الاقتصاد المعرفي في محتوى كتاب الحاسوب للصف الثاني متوسط، ثم مقارنة نتائجها مع النسب المحكية التي اتفق عليها المحكمين والمختصين من اجل تفسير النتائج والجدول (4) يوضح التكرارات والنسب الهئوية لهؤشرات المهارات الاساسية في محتوى كتاب الحاسوب للصف الثاني متوسط, والجدول (5) يوضح تكرارات مؤشرات مهارات الاتصال ونسب تضمينها, والجدول (6) يوضح تكرارات مؤشرات مهارات التفكير ونسب تضمينها في المحتوى, والجدول (7) يوضح تكرارات مؤشرات مهارات العمل الجماعي والنسبة المئوية لتضمينها في محتوى الكتاب, أما الجدول (8) يوضح تكرارات لمؤشرات مهارات جمع المعلومات وتنظيمها ونسب تضمينها, والجدول (9) يوضح عدد تكرارات والنسب الهئوية لهؤشرات الههارات السلوكية, ثم توضح الباحثة في الجدول (10) تكرارات مهارات الاقتصاد المعرفي مجتمعة ونسب تضمينها في محتوى كتاب الحاسوب للثاني

متوسط, لتقويم نتائجها. جدول رقم (4) يوضح التكرارات والثسب المئوية لمؤشرات المهارات الاساسية في محتوى كتاب الحاسوب للصف الثاني

\begin{tabular}{|c|c|c|c|c|c|c|}
\hline \multicolumn{7}{|r|}{ متوسط } \\
\hline \multicolumn{7}{|r|}{ المهارات الاساسية الماسة } \\
\hline \multicolumn{7}{|c|}{ المحور: القراءة والكتابة والمهارات الاساسية في تشغيل الحاسوب } \\
\hline 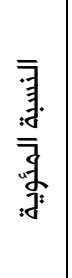 & 乌. & 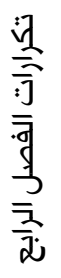 & 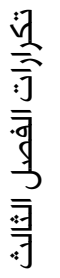 & 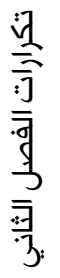 & 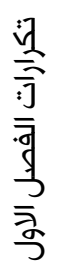 & 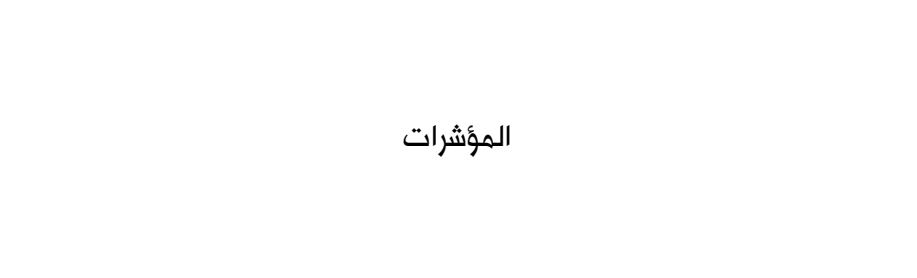 \\
\hline 13.3 & 58 & 5 & 7 & 6 & 40 & يشجع الطالب على قراءة الموضوع بدقة للتوصل الى فهمه بإتقان. \\
\hline 38.2 & 167 & 21 & 17 & 28 & 101 & الدراسي. الاشكال والصور التوضيحية التي تمكن الطالب من فهم الموضوع \\
\hline 3.2 & 14 & 2 & 3 & 3 & 6 & يربط الموضوع السابق بالموضوع اللاحق بشكل يلائم مستوى الطالب. \\
\hline 3.7 & 16 & 1 & 8 & 3 & 4 & يشجع الطالب على التعلم الذاتي. \\
\hline 1.1 & 5 & 0 & 3 & 2 & 0 & يعزز قدرة الطالب على طرح امثلة وافكار جديدة. \\
\hline 30.7 & 134 & 17 & 7 & 20 & 90 & يراعي التوازن بين الجانب العملي والجانب النظري. \\
\hline 6.2 & 27 & 0 & 0 & 0 & 27 & استخدام العمليات الحسابية و المنطقية مثل (+, *, / , -, >,>, = ). \\
\hline 3.4 & 15 & 0 & 4 & 0 & 11 & يشجع الطلبة في الحصول على المعرفة من خلال الحاسب الالي. \\
\hline
\end{tabular}

عبد، هاله محمد. (2019). تقويه محتوى كتاب الحاسوب للصف الثاني متوسط في ضوء مهارات الاقتصاد المعرفي. doi.org/10.36371/port.2018.02.3.10 J Journal Port Science Research 
j. port. sci. res.
ISSN: $2616-7441$
ISSN: $2616-6232$

\begin{tabular}{|c|c|c|c|c|c|c|}
\hline 0.2 & 1 & 0 & 1 & 0 & 0 & يعزز قدرة الطالب على التعبير اللفظي والمنطقي. \\
\hline 100 & 437 & 46 & 50 & 62 & 279 & المجموع \\
\hline
\end{tabular}

المهارات الاساسية (المحور القراءة و الكتابة والههارات الاساسية في تشغيل الحاسوب) حصل مؤشر (عرض الاشكال والصور التوضيحية التي تمكن الطالب من فهم الموضوع الدراسي) على أعلى عدد تكرارات بلغت (167) تكرارا" وبنسبة مئوية (38.2\%), لأهميتها في إثارة اهتمام الطالب وتثبت معلوماته التي يحصل عليها من خلالها, حيث تشكل الدعم الحسي للمفاهيم المجردة وتجذب انتباه الطلبة وتساعدهم في الوصول الى التفكير الاستنتاجي من خلال المعلومات البصرية, إما المؤشرات (يعزز قدرة الطالب على التعبير اللفظي والمنطقي) و(يعزز قدرة الطالب على طرح امثلة وافكار جديدة) و(يربط الموضوع السابق بالموضوع اللاحق بشكل يلائم مستوى الطالب) و(يشجع الطلبة في الحصول على المعرفة من خلال الحاسب الالي) فقد حصلت على اقل التكرارات, رغم اهميته هذه المؤشرات في تنمية مهارات الطلبة وقدراتهم المعرفية وتعزز قدرتهم في التعبير الكتابي واللفظي من خلال تطوير الخيال لديهم وكيفية تنظيم البيانات والمعلومات للوصول الى ثروة لغوية حتى يتمكن الطالب من صياغة الافكار وطرحها بشكل منطقي ومتسلسل وتشجيعه في الحصول على المعرفة والمعلومات من خلال الحاسب الالي مما ينمي لدية مهارات البحث الذاتي وتنشيط دافعيته نحو التعلم والانفتاح على احدث المعلومات وتزيد من التفاعل بين الطلبة من خلال الهناقشات الصفية التي تدور بينهم وعند القيام بالأعمال الجماعية التي تعد نقطة انطلاق لطاقاتهم الابتكارية والابداعية, لذا كان من الضروري تضمين تلك الهؤشرات بنسب عالية في محتوى كتاب الحاسوب للصف الثاني متوسط وتعزيز المؤشرات الاخرى التي لا تقل اهميتها عن باقي الهؤشرات . جدول (5) يوضح التكرارات والنسب المئوية لمؤشرات مهارات الاتصال في محتوى كثاب الحاسوب للصف الثاني متوسط

\begin{tabular}{|c|c|c|c|c|c|c|}
\hline \multicolumn{7}{|r|}{ 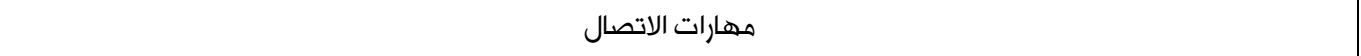 } \\
\hline \multicolumn{7}{|c|}{ المحور: التعبير الشفوي والحوار والاقناع والاستثارة } \\
\hline 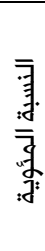 & 亲. & 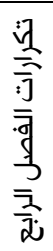 & 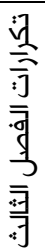 & 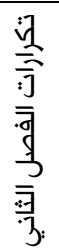 & 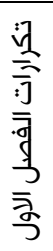 & المؤشرات \\
\hline 46 & 17 & 2 & 4 & 7 & 4 & يساعد الطالب على إدراك الفكرة الرئيسة من الموضوع الدراسي المعروض \\
\hline 19 & 7 & 1 & 1 & 0 & 5 & ينمي مهارة التجريب لدى الطالب \\
\hline 0 & 0 & 0 & 0 & 0 & 0 & الحصول على معلومات من خلال المواقع الالكترونية \\
\hline 0 & 0 & 0 & 0 & 0 & 0 & يعزز قدرة الطالب على مناقشة الافكار المعروضة \\
\hline
\end{tabular}

Abed, H. (2019). Evaluating the Content of The Second Grade Computer Book in The Light of The Skills of Knowledge Economy. Journal Port Science Research, 2(3), 509-536. doi.org/10.36371/port.2018.02.3.10 
j. port. sci. res.
isSN: $2616-7441$

\begin{tabular}{|c|c|c|c|c|c|c|}
\hline & & & & & & استخدام التعبير اللفظي أو الغير اللفظي أو المزج بينهما هما يثير انتباه \\
\hline נכ & 15 & 2 & 2 & 3 & 0 & الطلبة \\
\hline 0 & 0 & 0 & 0 & 0 & 0 & البحث عن المعلومات باستخدام الوسائل التقنية \\
\hline 100 & 37 & 5 & 7 & 10 & 15 & الهجموع \\
\hline
\end{tabular}

مهارات الاتصال (المحور التعبير الشفوي والحوار والاقناع والاستثارة) حصل مؤشر (يساعد الطالب على ادراك الفكرة الرئيسة من الموضوع الدراسي المعروض) على أكثر التكرارات بين المؤشرات حيث بلغ (17) تكرار وبنسبة (46\%), على الرغم من الكتاب المدرسي الجيد يحتم على ان تتصدر الفكرة الرئيسة من الموضوع المعروض للطالب لتساعده في ادراك البنية الكلية للموضوع الا ان هذا المؤشر لم يتضمن بنسب عالية في محتوى كتاب الحاسوب للثاني متوسط, وحصلت المؤشرات التالية (استخدام التعبير اللفظي أو الغير اللفظي أو الهزج بينهما مما يثير انتباه الطلبة) و(ينمي مهارة التجريب لدى الطالب) على ادنى عدد من التكرارات, رغم اهميتها في تقوية المفردات اللغوية لدى الطلبة وتزيد من ثقتهم بنفسهم وتساعدهم على ادراك الذات وتمكنهم من تطبيق المعرفة التي يكتسبونها في مواقف مختلفة والبحث عن النتائج الجديدة وتدعم الخيال في تفكيرهم وبذلك لم تنل هذه المؤشرات اهتمام كبير في المحتوى, أما المؤشرات (الحصول على معلومات من خلال المواقع الالكترونية) و (يعزز قدرة الطالب على مناقشة الافكار المعروضة)و(البحث عن المعلومات باستخدام الوسائل التقنية) فقد اهملت ثلاث مؤشرات من اصل ست مؤشرات لمهارات الاتصال, ولما لها أهمية بالغة في ربط الطالب بالواقع العلمي والانتاج الفكري وتوفر الفرصة الكافية لتحقيق النمو الهتكامل للطالبة مراعية الفروق الفردية بين قدراتهم واستعداداتهم وهيولهم, الا انها لم تراع في محتوى كتاب الحاسوب للصف الثاني متوسط. جدول (6) يوضح التكرارات والنسب المئوية لمؤشرات مهارات التفكير في محتوى كتاب الحاسوب للصف الثاني متوسط

\begin{tabular}{|c|c|c|c|c|c|c|}
\hline \multicolumn{7}{|c|}{ مهارات التفكير } \\
\hline \multicolumn{7}{|c|}{ الهحور: الههارات معرفية والههارات الغير معرفية } \\
\hline 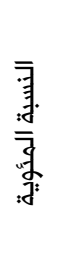 & 亲 & 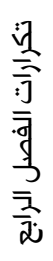 & 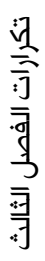 & 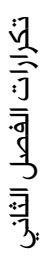 & 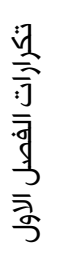 & 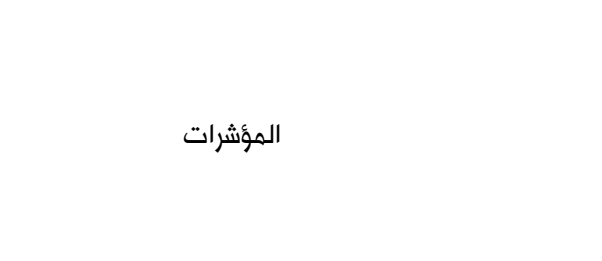 \\
\hline 14.3 & 39 & 7 & 8 & 9 & 15 & يعرض المحتوى التفاصيل المكونة للموضوع \\
\hline 10.6 & 29 & 1 & 5 & 15 & 8 & يساعد على ايجاد العلاقات بين الاجزاء او بين الجزء والكل \\
\hline 0 & 0 & 0 & 0 & 0 & 0 & ينمي مهارتي حل المشكلات واتخاذ القرارات لدى الطلبة \\
\hline
\end{tabular}

عبد، هاله محمد. (2019). تقويم محتوى كتاب الحاسوب للصف الثاني متوسط في ضوء مهارات الاقتصاد المعرفي. doi.org/10.36371/port.2018.02.3.10 J Journal Port Science Research 
j. port. sci. res.
isSN: $2616-74$

\begin{tabular}{|c|c|c|c|c|c|c|}
\hline 9.2 & 25 & 0 & 7 & 4 & 14 & عرض انشطة او تمارين تثير دافعية الطالب لحلها بشكل علمي وصائب. \\
\hline 25.6 & 70 & 7 & 23 & 17 & 23 & عرض اسئلة تقيس المجالات المعرفية والوجدانية والمهارية. \\
\hline 20.9 & 57 & 0 & 21 & 16 & 20 & عرض انشطة او اسئلة بعيدة عن التخمين. \\
\hline 16.8 & 46 & 7 & 12 & 16 & 11 & يشجع الطالب على استرجاع المعلومات السابقة. \\
\hline 0 & 0 & 0 & 0 & 0 & 0 & ينمي مهارة التقويم واصدار الاحكام لدى الطلبة. \\
\hline 0 & 0 & 0 & 0 & 0 & 0 & حث الطلبة على استخدام مصادر مختلفة في الحصول على المعرفة \\
\hline 2.6 & 7 & 1 & 1 & 4 & 1 & ينمي مهارة المقارنة لدى الطالب \\
\hline 100 & 273 & 23 & 77 & 81 & 92 & المجموع \\
\hline
\end{tabular}

مهارات التفكير (المحور المهارات معرفية والمهارات الغير معرفية) حصل مؤشر (عرض اسئلة تقيس المجالات المعرفية والوجدانية و المهارية) على أعلى التكرارات بلغت (70) تكرارا" وبنسبة مئوية (25.6\%), لأهميتها في دعم نوعية المعلومات المطروحة والمهمة وتبين المعاني والقضايا بطريقة الاستقصاء من خلال طرح وصياغة الاسئلة الفاعلة التي تؤدي الى عملية الفهم الاوسع للظاهرة بهدف توليد معلومة جديدة, وبالتالي ينمي هذا المؤشر مهارة البحث عند الطالب وتزيد من قدرته العقلية, إما المؤشرات (ينمي مهارة المقارنة لدى الطالب) و(عرض انشطة او تمارين تثير دافعية الطالب لحلها بشكل علمي وصائب) و(يساعد على ايجاد العلاقات بين الاجزاء او بين الجزء والكل) حصلت على ادنى عدد من التكرارات, رغم الأهمية التي تتضمنها هذه المؤشرات حيث تعزز قدرة الطالب على تنظيم الافكار بطريقة متسلسلة للقيام بعمليات التحليل والربط والتفسير والاستنتاج بهدف توليد معلومات يمكن تطبيقها في مواقف اخرى, وتتيح فرصة التعلم الذاتي للطالب مؤدية الى عمليات الاكتشاف والبحث والتساؤل, الا ان تلك المؤشرات لم تنال الاهتمام الكبير في محتوى كتاب الحاسوب للثاني متوسط, أما المؤشرات التي اهملت ولم تحصل على تكرار فهي (ينمي مهارتي حل المشكلات واتخاذ القرارات لدى الطلبة) و(ينمي مهارة التقويم واصدار الاحكام لدى الطلبة)و(حث الطلبة على استخدام مصادر مختلفة في الحصول على المعرفة), التي تعد من اهم المؤشرات الواجب تزويد الطلبة بها لأنها تزودهم بإطار عمل قائم على تحليل افكارهم في المواقف التي تتطلب مواجهة المشكلات وتدفعه الى البحث والتحري والاكتشاف وايجاد الحلول المناسبة لها ,وتزويد الطالب بمثل تلك المؤشرات تعد ضرورة لابد منها, لأنها تنمي مهاراته العقلية وترفع من مستواه العلمي والمعرفي وتمكنه من اصدار الاحكام وفق معايير معينه وفي ضوء نتائجها يتم اتخاذ القرارات المناسبة, وعدم تضمينها في محتوى كتاب الحاسوب للثاني متوسط يدل على عدم الالتزام بمعايير الجودة عند أعداد 
j. port. sci. res.
ISSN: $2616-7441$ Volume:2, No:3

\begin{tabular}{|c|c|c|c|c|c|c|}
\hline \multicolumn{6}{|c|}{ جدول (7) يوضح/الثكرارات والثسب المئوية لمؤشرات مهارات العمل الجماعي في محثوى كثاب الحاسوب للصف الثاني متوسط } & 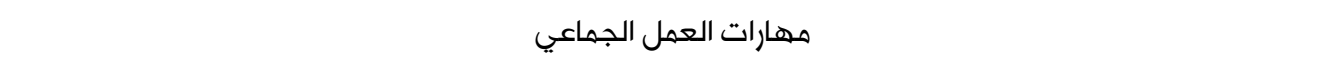 \\
\hline \multicolumn{7}{|c|}{ المحور: التعاون مع الاخرين والعمل في فرق } \\
\hline 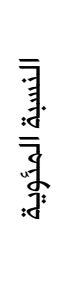 & 京 & 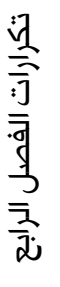 & 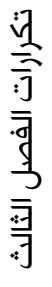 & 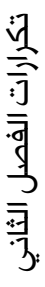 & 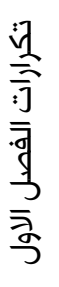 & 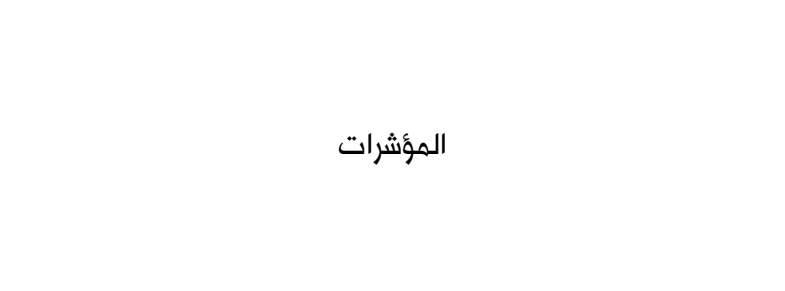 \\
\hline 0 & 0 & 0 & 0 & 0 & 0 & طرح انشطة او اسئلة تتطلب مناقشة صفية بين الطلبة \\
\hline 0 & 0 & 0 & 0 & 0 & 0 & 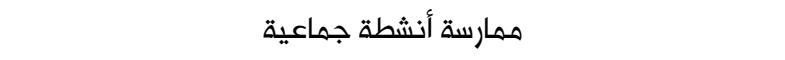 \\
\hline 87.5 & 28 & 1 & 10 & 6 & 11 & طرح أنشطة أو أسئلة او تمارين تتفاوت في صعوبتها لتراعي الفروق \\
\hline 12.5 & 4 & 0 & 3 & 1 & 0 & 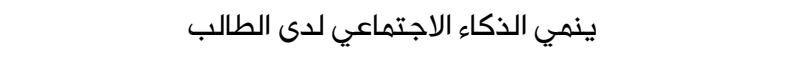 \\
\hline 0 & 0 & 0 & 0 & 0 & 0 & طرح انشطة تربط العلم بالبيئة والمجتمع \\
\hline 100 & 32 & 1 & 13 & 7 & 11 & 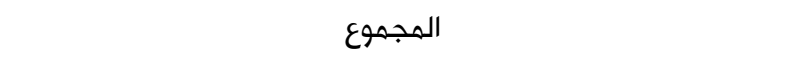 \\
\hline
\end{tabular}

مهارات العمل الجماعي (المحور التعاون مع الاخرين والعمل في فرق) نال المؤشر(طرح أنشطة أو أسئلة او تمارين تتفاوت في صعوبتها لتراعي الفروق الفردية بين الطلبة) على أعلى عدد تكرارات بلغ (28) تكرار وبنسبة ( 87.5٪), الا ان هذا المؤشر لم يحصل على الاهتمام الكبير, رغم كونه من اهم اهداف تدريس رس مادة الحاسوب للمرحلة المتوسطة ان يراعي الفروق الفردية بين الطلبت, وأي اهمال لهذا المؤشر يؤدي الى أثار سلبية تعوق تحقيق الاهداف التعليمية وتؤثر على المستوى العلمي والاجتماعي للطلبة, أما المؤشر الذي حصل على ادنى التكرارات هو (ينمي الذكاء الاجتماعي لدى الطالب) حيث بلغ (4) تكرار وبنسبة (12.5\%), (غم كونه ينمي اهم مهارة تلبي احتياجات الطالب الاجتماعية والعاطفية التي تقوده الى تطوير ذاته, فقد اشارت دراسات تربوية الى ان تنمية الذكاء الاجتماعي لدى الطالب يؤدي الى تنميه مهارات التفكير الابداعي لوجود علاقة ايجابية وطردية بين الابداع والذكاء الاجتماعي, لذا كان من المفروض ان ينال هذا المؤشر اهتمام كبير من قبل مؤلفي هذا الكتاب, أما المؤشرات التي اهملت ولم تنال على اي تكرار هي (طرح انشطة او اسئلة تتطلب مناقشة صفية بين الطلبة) و(ممارسة أنشطة جماعية) و(طرح انشطة تربط العلم بالبيئة والمجتمع) ولم يراع محتوى كتاب الحاسوب للثاني متوسط تضمين هذه 
المؤشرات, رغم كونها من أهم المؤشرات التي تضمن مشاركة الطلبة في مجاميع وضمن فرق واسهامهم فيه ينمي مهارات التفكير لديهم والتحليل العميق للأنشطة يشجعهم على مناقشة مختلف الموضوعات مع زملائهم وطرح افكارهم المتنوعة واثارة انتباه الطلبة وتهدف الى بناء الشخصية الابداعية والمتكاملة. جدول (8) يوضح التكرارات والنسب المئوية لمؤشرات مهارات جمع وتنظيم المعلومات في محتوى كتاب الحاسوب للصف الثاني متوسط

\begin{tabular}{|c|c|c|c|c|c|c|}
\hline \multicolumn{7}{|c|}{ مهارات جمع المعلومات وتنظيمها } \\
\hline \multicolumn{7}{|c|}{ المحور: مهارات جمع وتنظيم المعلومات } \\
\hline 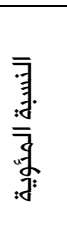 & ఫુ & 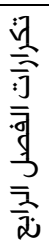 & 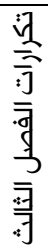 & 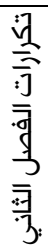 & 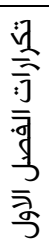 & المؤشرات \\
\hline 2 & 4 & 0 & 2 & 0 & 2 & يقدم عنصر التشويق قبل عرض المادة العلمية \\
\hline 36.4 & 71 & 7 & 9 & 10 & 45 & تشجيع الطلبة على استخدام الحواس في الحصول على معلومات \\
\hline 3.1 & 6 & 0 & 2 & 3 & 1 & تنظيم المعلومات بأشكال او مخططات وعرضها بشكل سلس \\
\hline 12.3 & 24 & 2 & 6 & 0 & 16 & تطبيق المعرفة المتاحة في الحصول على معارف جديدة \\
\hline 46.2 & 90 & 7 & 7 & 8 & 68 & ينمي مهارة الملاحظة وصياغة الاسئلة لدى الطالب \\
\hline 100 & 195 & 16 & 26 & 21 & 132 & المجموع \\
\hline
\end{tabular}

مهارات جمع المعلومات وتنظيمها (المحور مهارات جمع وتنظيم المعلومات) فقد حصل

مؤشر(ينمي مهارة الملاحظة وصياغة الاسئلة لدى الطالب) على أكثر عدد تكرار حيث بلغت (90) تكرارا وبنسبة ( 46.2\%), لكونها تسهم في إبقاء أثر ما تم تعلمه لفترة أطول, حيث اثبتت الدراسات والابحاث الخاصة بالدماغ ان اهم حاسة هي حاسة البصر في استقبالها للمعلومات حيث تشكل (85 \%) من مدخلات الحسية للمخ, لذا فهي تسهم في أثارة النشاطات الذهنية للطلبة وتزيد من قدرتهم العقلية وتمكنهم من تطوير ما تم تعلمة بدءا" بالنشاطات الاستقصائية الى الاستدلالات الجديدة, بينما المؤشرات التي نالت ادنى التكرارات ضمن مهارات جمع المعلومات وتنظيمها هي (يقدم عنصر التشويق قبل عرض الهادة العلمية) و(تنظيم المعلومات بأشكال او مخططات وعرضها بشكل سلس ), رغم اهمية هذه المؤشرات التي تجعل تفكير الطالب استقرائي التعلم, أي يتم ترسيخ ما تم تعلمة في ذهن الطالب لمدة أطول من المعلومات التي تقدم عن طريق الاصغاء والقراءة وتمكن الطالب من استخراج القواعد والاحكام المتعلقة بموضوع معين واستخراج العناصر المشتركة بينها ويكشف العلاقات المتواجدة بين المتغيرات و يطبقها للوصول الى معلومات جديدة, وتنمي لدية اتجاهات وعادات عقلية ونفسية سليمة كالقدرة على مواجهة المشكلات والتشويق لاكتشاف الحقائق وتكوين النتائج والاحكام العامة, الا ان محتوى كتاب الحاسوب لم يراعها الاهتمام لذي تستحقه. 
جدول (و) يوضح التكرارات والثسب المئوية لمؤشرات مهارات السلوكية في محتوى كتاب الحاسوب للصف الثاني متوسط

\begin{tabular}{|c|c|c|c|c|c|c|}
\hline \multicolumn{7}{|c|}{ المهارات السلوكية } \\
\hline \multicolumn{7}{|c|}{ المحور: الابتكار والابداع والتجدد وتكوين فكرة والدفاع عنها وتحمل المسؤولية } \\
\hline $\begin{array}{l}\text { 旾 } \\
\text { : } \\
\text { 雪 }\end{array}$ & گ. & $\begin{array}{l}\frac{17}{1} \\
\frac{1}{1} \\
\overline{3} \\
\frac{7}{3} \\
\frac{1}{2} \\
\overline{2}\end{array}$ & 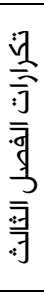 & 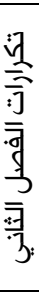 & 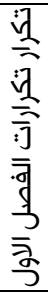 & 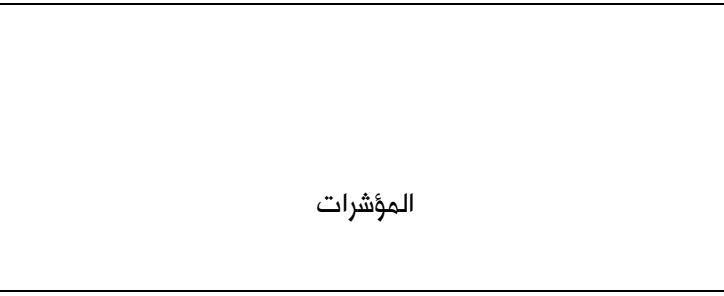 \\
\hline 0 & 0 & 0 & 0 & 0 & 0 & ينمي الاتجاهات الايجابية لدى الطلبة نحو العلم والعلماء \\
\hline 0 & 0 & 0 & 0 & 0 & 0 & تعزيز مشاركة الطلبة في خدمة المجتمع \\
\hline 0 & 0 & 0 & 0 & 0 & 0 & تشجيع الطلبة على تحمل المسؤولية عند القيام بالتجارب العلمية \\
\hline 0 & 0 & 0 & 0 & 0 & 0 & التكيف مع متغيرات العصر ومواكبتها \\
\hline 0 & 0 & 0 & 0 & 0 & 0 & يشجع على المنافسة بين الاقران والدفاع عن آراءهم \\
\hline 13 & 2 & 0 & 0 & 0 & 2 & ينمي مهارة الابتكار \\
\hline 87 & 13 & 0 & 4 & 3 & 6 & ينمي مهارة الابداع لدى الطلبة من خلال تقديم حلول متعددة لنشاط \\
\hline 100 & 15 & 0 & 4 & 3 & 8 & المجموع \\
\hline
\end{tabular}

المهارات السلوكية (المحور الابتكار والابداع والتجدد وتكوين فكرة والدفاع عنها وتحمل المسؤولية) حصل مؤشر(ينمي مهارة الابداع لدى الطلبة من خلال تقديم حلول متعددة لنشاط او سؤال معين) على أعلى التكرارات بين مؤشرات المهارات السلوكية حيث بلغ (13) تكرار وبنسبة (87\%), الا انه لم يتضمن في محتوى كتاب الحاسوب للثاني متوسط بنسب عالية, رغم اهمية هذ المؤشر كونه يمكن الطالب من استخدام الامكانيات المتاحة لتحقيق الاهداف المخطط لها والحصول على النتائج المأمولة, والتفوق في فهم الامور سواء كانت علمية او عملية القدرة على عرض الافكار الغير مسبوقة والتغلب على العقبات والمشكلات القائمة, أما مؤشر(ينمي مهارة الابتكار) فقد نال على ادنى التكرارات, رغم انه يزيد من قدرة الطالب على التجديد في الاداء والعلم والتقنية والافكار وغيرها, وتمكنه من تحويل الافكار التطويرية والابداعية الى تطبيقات عملية فالإبداع يقود الى الابتكار, لذا كان من المفروض ان كتاب الحاسوب يتضمن هاتين المهارتين بنسب عالية لكون مادة الحاسوب ديناميكية قابله للتطوير السريع في عصرنا الحالي, أما مؤشرات التي لم تنل اي تكرار هي(ينمي الاتجاهات الايجابية لدى الطلبة نحو العلم والعلماء) و(تعزيز مشاركة الطلبة في خدمة المجتمع) 
و(تشجيع الطلبة على تحمل المسؤولية عند القيام بالتجارب العلمية) و(التكيف مع متغيرات العصر

ومواكبتها) و(يشجع على المنافسة بين الاقران والدفاع عن آراءهم) لذا فان خمس مؤشرات اهملت من اصل سبع مؤشرات للمهارات السلوكية , وبذلك يقل تأثير دور هذا الكتاب في رفع المستوى المعرفي والوجداني والمهارى للطلبة, لذا لابد من اعادة النظر فيه وإعداده وفق معايير جودة الكتاب المدرسي ليحقق الاهداف التعليمية المرجوة منه.

جدول رقم (10) يوضح/التكرارات والنسب الهئوية لمهارات الاقتصاد المعرفي مجتمعة في محتوى كثناب الحاسوب للصف الثاني

\begin{tabular}{|c|c|c|c|}
\hline \multicolumn{4}{|c|}{ متوسط } \\
\hline الرتبة الر & النسبة المئوية & التكرار & ههارات الاقتصاد المعرفي \\
\hline 1 & 44.3 & 437 & مهارات الاساسية \\
\hline 4 & 3.7 & 37 & هـهارات الاتصال \\
\hline 2 & 27.6 & 273 & مهارات التفكير \\
\hline 5 & 3.2 & 32 & ههارات العمل الجماعي \\
\hline 3 & 19.7 & 195 & ههارات جمع وتنظيم المعلومات \\
\hline 6 & 1.5 & 15 & مهارات السلوكية \\
\hline & 100 & 989 & 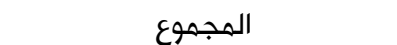 \\
\hline
\end{tabular}

جدول (10) يوضح التكرارات والنسب المئوية لكل مهارة من مهارات الاقتصاد المعرفي مجتمعة في محتوى كتاب الحاسوب للصف الثاني متوسط وقد توزعت بصورة متفاوتقة حيث جاءت المهارات الاساسية بعدد تكرارات (437) وبنسبة مئوية (44.3\%) لذا فقد نالت المرتبة الأولى بين مهارات الاقتصاد المعرفي, وعند مقارنتها بالنسبة المحكية التي تم الاتفاق عليها من قبل المختصين والهحكمين, فقد جاءت بدرجة تقويم ضعيف ويرجع السبب في ذلك لأنه ركز على بعض الهؤشرات منها (عرض الاشكال والصور التوضيحية التي تمكن الطالب من فهم الموضوع الدراسي, يراعي التوازن بين الجانب العملي والجانب النظري, يشجع الطالب على قراءة الموضوع بدقة للتوصل الى فهمه بإتقان) واهتم اهتماما" ضعيفا" بمؤشرات أخرى مثل (يعزز قدرة الطالب على التعبير اللفظي والمنطقي, يعزز قدرة الطالب على طرح امثلة وافكار جديدة, يربط الموضوع السابق بالموضوع اللاحق بشكل يلائم مستوى الطالب). أما المرتبة الثانية فقد حصلت عليها مهارات التفكير حيث بلغت تكراراتها (273) وبنسبة مئوية (27.6٪)، أي بدرجة تقويم ضعيف لان المحتوى اهمل ثلاث مؤشرات من أصل عشرة مؤشرات، وركز على مؤشر (عرض اسئلة تقيس الهجالات المعرفية والوجدانية والمهاريه) واهتم بالمؤشرات الأخرى مثل (ينمي مهارة المقارنة لدى الطالب، عرض انشطة او تمارين 
تثير دافعية الطالب لحلها بشكل علهي وصائب, يساعد على ايجاد العلاقات بين الاجزاء او بين الجزء والكل) اهتماما" ضعيفا.

وجاءت مهارات جمع وتنظيم المعلومات بالمرتبة الثالثة بعدد تكرارات (195) وبنسبة مئوية (19.7 \%) وجاء بدرجة تقويم ضعيف لان هذه المهارات ركزت على مؤشرين هما (ينمي مهارة الملاحظة وصياغة الاسئلة لدى الطالب، تشجيع الطلبة على استخدام الحواس في الحصول على معلومات) بينما اهتمت اهتمام ضعيف بمؤشرات (يقدم عنصر التشويق قبل عرض المادة العلمية، تنظيم المعلومات بأشكال او مخططات وعرضها بشكل سلس). وحصلت مهارات الاتصال على الهرتبة الرابعة بين مهارات الاقتصاد المعرفي بلغت عدد تكراراتها (37) وبنسبة مئوية (3.7\%), اي بدرجة تقويم ضعيف لأنها أهملت ثلاث مؤشرات من أصل ست مؤشرات وركزت على مؤشر (يساعد الطالب على إدراك الفكرة الرئيسة من الموضوع الدراسي المعروض) وحصلت باقي المؤشرات على اهتمام ضعيف. بينما جاءت مهارات العمل الجماعي بالمرتب الخامس بعدد تكرارات (32) وبنسبة مئوية (3.2\%)، وجاءت بدرجة تقويم ضعيف لان هذه المهارات أهملت ثلاث مؤشرات من أصل خمس مؤشرات ولم تحصل على اي تكرار، واهتمت اهتمام ضعيف بالمؤشرين الباقين وهما (طرح أنشطة أو أسئلة او تمارين تتفاوت في صعوبتها لتراعي الفروق الفردية بين الطلبة، يذمي الذكاء الاجتماعي لدى الطالب)

وحصلت المهارات السلوكية على الهرتبة السادسة والاخيرة حيث بلغت عدد تكراراتها (15) وبنسبة مئوية (1.5\%) فقد جاءت بدرجة تقويم ضعيف، ويعود السبب في ذلك لأنها اهملت خمس مؤشرات من أصل سبعة مؤشرات ولم تحصل على أي تكرار، ولم تهتم بالمؤشرين الاخرين اهتمام كبير انما جاءت بنسب قليلة مثل (ينمي مهارة الابداع لدى الطلبة من خلال تقديم حلول متعددة لنشاط او سؤال معين) بلغت عدد تكراراته (13) وبنسبة (87 \%) و (ينمي مهارة الابتكار) جاء بعدد تكرارات (2) وبنسبة مئوية (13 \% \%). لذا ترى الباحثة أن محتوى كتاب الحاسوب للثاني متوسط يحتاج الى إعادة النظر فيه لأنه جاء بنسب ) غير متوازنة لمهارات الاقتصاد المعرفي ولم يراعها مما يدل على ضعف دوره في مساعدة الطلبة على رفع مستواهم العلمي والتقني ومواكبة التطورات السريعة الحاصلة في مجالي العلم والتكنولوجية, ويدل على تعطيل دور الانظمة التربوية في تحقيق اهدافها في نقل الطالب من دوره التقليدي والمستهلك للمعرفة الى دور اكثر فاعلية وايجابيه ومنتج للمعرفة, ومن اجل اكمال هذا التحول يجب ان تتوافق المناهج الدراسية مع متطلبات سوق العمل, لذا على الانظمة التعليمية ان تتبنى مواكبة هذه التطورات في ظل التحديات العالهية الحديثة.

عبد، هاله محمد. (2019). تقويه محتوى كتاب الحاسوب للصف الثاني متوسط في ضوء مهارات الاقتصاد المعرفي. doi.org/10.36371/port.2018.02.3.10 J Journal Port Science Research 
1) توزعت مهارات الاقتصاد المعرفي بشكل عشوائي ومتفاوت، ويدل ذلك على عدم وجود منهجية مسبقة لكتاب الحاسوب للثاني متوسط لكيفية تضمينه تلك المهارات.

2) حصلت جميع مهارات الاقتصاد المعرفي على درجة تقويم ضعيف في محتوى كتاب الحاسوب للثاني متوسط وحسب الترتيب الاتي (المهارات الاساسية، مهارات التفكير، مهارات جمع المعلومات وتنظيمها، وههارات الاتصال، ومهارات العمل الجماعي، مهارات السلوكية). 3) تم اهمال (14) مؤشر من أصل (42) مؤشر دالة على مهارات الاقتصاد المعرفي، وهذا يدل على ضعف كتاب الحاسوب في مواكبته للتطورات الحاصلة في مجالي العلم والتكنولوجية. 4) تم الاهتمام ببعض المؤشرات اهتماما' ضعيفا'، حيث جاءت بعدد تكرارات ونسب مئوية قليلة، وهذا يدل على الاهمال الواضح لتلك الهؤشرات مثل (يعزز قدرة الطالب على التعبير اللفظي والهنطقي، يعزز قدرة الطالب على طرح امثلة وافكار جديدة، ينمي مهارة التجريب لدى الطالب، ينمي مهارة المقارنة لدى الطالب، ينمي الذكاء الاجتماعي لدى الطالب، يقدم عنصر التشويق قبل عرض المادة العلمية، تنظيم المعلومات بأشكال او مخططات وعرضها بشكل سلس, ينمي مهارة

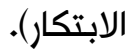

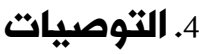

مراعاة التوازن في تضمين مهارات الاقتصاد المعرفي في محتوى كتاب الحاسوب للثاني متوسط لها لها من دور في مواكبة التطورات السريعة في التقنيات الحديثة والتحديات التي يواجهها المجتمع في عصر الاقتصاد المعرفي. الاهتمام بمؤشرات المهارات التي أهملت والعمل على تضمينها وتعزيز مؤشرات المهارات التي نالت اهتماما" ضعيفا" في محتوى كتاب الحاسوب. والاهتمام بمهارات الاقتصاد المعرفي التي جاءت بدرجة تقويم ضعيف واعادة النظر في محتوى الكتاب بما يتوافق مع تلك المهارات. الاستفادة من قائمة مهارات الاقتصاد المعرفي في البحث الحالي لإجراء دراسات أخرى للمناهج الدراسية ولمختلف المراحل التعليمية. أقامه دورات تدريبية لمدرسي وهدرسات مادة الحاسوب لزيادة وعيهم بأهمية مهارات الاقتصاد المعرفي والكشف عنها وتدريبهم على تنميتها لدى الطلبة. 


$$
\text { إجراء دراسات تقويمية أخرى لهحتوى كتب الحاسوب وفق مهارات الاقتصاد المعرفي للمراحل }
$$

إجراء دراسات مماثلة لمحتوى كتاب الحاسوب ولجميع المراحل التعليمية في ضوء مهارات الاقتصاد

إجراء دراسة لمعرفة إثر توظيف مهارات الاقتصاد المعرفي في تنمية التفكير الابداعي والابتكاري لدى الطلبة بمادة الحاسوب للصف الثاني متوسط.

اجراء دراسة مقارنة بين كتب الحاسوب التي تدرس للمرحلة المتوسطة في العراق وكتب الحاسوب التي تدرس للمرحلة المتوسطة في باقي البلدان العربية وفق مهارات الاقتصاد المعرفي.

\section{References}

[1] Iraqi Ministry of Education (2009). > الاهداف العامة الخاصة لتدريس العلوم في المرحلة المتوسطة >. General Directorate of Curricula, Republic of Iraq. manahj.edu.iq

[2] Ali, Shadi (2018). تطوير التعليم الجامعي في العراق - افاق وحلول في ضوء التجارب الدولية> https:/ / books.google.iq/books?id=CzJ3DwAAQBAJ\&pg=PP1\&lpg=PP1\&dq=

[3] Iraqi Ministry of Education (2009). الاهداف والمفردات الخاصة بمنهج الحاسوب> . General Directorate of Curricula, Republic of Iraq. manahj.edu.iq

[4] Al-Hashemi, Abdulrahman and Faiza Mohammad Al-Azzawi (2007). المنهج والاقتصاد المعرفي> > 1st Floor, Al-Masirah Publishing and Distribution, Amman, Jordan.

http:/ / www.damascusuniversity.edu.sy/mag/law/images/stories/1-2012/a/591-610.pdf

[5] Al-Qara'a, Ahmad Odeh and Hakam Ramadan Juma (2017). فاعلية برنامج قائم على التعلم المبرهج في تدريس العلوم في تحصيل طلبة للصف التاسع الاساسي وتنمية مهارات التفكير ما وراء المعرفي . Published Research, Journal of Educational and Psychological Sciences, Bahrain, Volume 19, Issue 2.

[6] Hariri, Rafida (2012) > التقويم التربوي > Dar Al-Manahj for Publishing and Distribution, Amman, Jordan.e1. https: / www.neelwafurat.com/itempage.aspx?id=lbb172506-135380\&search=books

[7] Attia, Mohsen Ali. (2013). الهناهج الحديثة وطرائق التدريس> Dar Al-Manaaj, Amman. e1. https:/ / www.neelwafurat.com/itempage.aspx?id=lbb181046-144331\&search=books.

[8] Salman, Fouad Daoud. (2019). تقويم محتوى كتاب اللغة العربية للصف الثاني متوسط من وجهة نظر الهدرسين. published research, Journal of the Conquest, No. 77.

عبد، هاله محمد. (2019). تقويم محتوى كتاب الحاسوب للصف الثاني متوسط في ضوء مهارات الاقتصاد المعرفي. doi.org/10.36371/port.2018.02.3.10 J Journal Port Science Research 
[9] Al-Samouk, Saadoun Mahmoud and Huda Ali. (2009). المناهج الدراسية بين التقليد والتحديث> Dar Al-Warraq, Amman. $\quad$ https://www.neelwafurat.com/itempage.aspx?id=lbb193737$\underline{163345 \& \text { search }=\text { books }}$

[10] Al-Tamimi, Awad Jassim Mohammed. (2011). > المنهج وتحليل الكتاب . Hawra Press for publication and distribution, Baghdad. e2. http://www.iraqnlaiq.com/opac/ fullrecr.php?nid=290383\&hl=ara

[11] Shafqa, Said Tawfik Said. (2013). مهارات الاقتصاد المعرفي المتضمنة في محتوى كتب العلوم للمرحلة . الاساسية العليا بغزة ومدى اكتساب طلبة الصف العاشر لها . Master Thesis, Islamic University of Gaza. https: / / iugspace.iugaza.edu.ps / browse?rpp=20\&sort_by=1\&type=title\&offset=9246\&etal=$\underline{1 \text { \&order }=\text { ASC\&locale-attribute }=\text { en }}$.

[12] Muslim, Mohsen Taher and Marwan Abdel Reda. (2017). تحليل كتب الفيزياء للمرحلة الاعدادية في ضوء مهارات الاقتصاد المعرفي ومدى المام المدرسين بها >. Uruk Journal of Human Sciences, Volume 10, No. 4. https: / / www.iasj.net/iasj?func $=$ article\&aId $=148000$

[13] Al-Qaisi, Mohammed Ali Bin Ahmed. (2011) ملامح الاقتصاد المعرفي المتضهنة في محتوى مقررات مالعلوم الشرعية في مشروع تطوير التعليم الثانوي بالهملكة العربية السعودية . unpublished master thesis, Mutah University, Saudi Arabia.

[14] Al-Maghrabi, Abdel Fattah (2002). نظم المعلومات الادارية> > 1st Floor, Modern Library for Printing and Distribution, Mansoura University. http:/ / eulc.edu.eg/eulc_v5/Libraries/start.aspx?fn=ApplySearch\&ScopeID=

[15] Khalaf, Falih Hassan (2007). > Modern Books World for Publishing and Distribution, Amman, Jordan. https://www.neelwafurat.com/itempage.aspx?id=lbb151595113089\&search=books.

[16] Marei, Tawfiq Ahmad and Mohammed Mahmoud resourceful. (2011). المناهج التربوية الحديثة > مفاهيمها وعناصرها واسسها وعملياتها > Dar Al-Masirah for Publishing and Distribution, Amman, Jordan. http:/ / 213.6.8.28:310/records/1/3804.aspx

[17] Diab, Mahdi and Nagwa Gamal El-Din. (2007) > الجامعة ومجتمع المعرفة: التحدي والاستجابة, مستقبل > . The First Annual Conference of the Arab Center for Science Development in cooperation with Ain Shams Group held in the period 5 May, c, 1 Cairo.(wep pdf) http://www.bu.edu.eg/portal/uploads/discussed thesis/11265187/11265187 R.pdf

[18] Shtatiha, Aisha. الاولوية التي يحتلها راس المال البشري في ظل الاقتصاد المعرفي>... Dar AlYazouri for Publishing and Distribution, Amman, Jordan.e1. https: / / faylasof.com/quickview/index/view/id/209868.

[19] Al-Titi, Khader Mosbah Ismail. (2009). ادارة المعرفة التحديات والتقنيات والحلول> Al-Hamed Publishing and Distribution, Amman. https: / www.noor-book.com. 
[20] Daft, R.L, < Organization Theory \& Design $>2^{\text {nd }}$ ED, West pub; San Francisco ,2001. https: / / www.biblio.com/organization-theory-and-by-daft-richard-1/work/112981

[21] Nouri, Haidar Shaker and Mahmoud Hassan Gomaa (2013). دراسات في أثر المعرفة وتكنولوجيا > a body published in the Journal of Management and Economics, University of Mustansiriya, volume (36), number (97). https: / / www.iasj.net / iasj?func=search\&query=au

[22] Barthes J.P.A., \& Tacla , C.A. , < Agent - Supported portals and know Ledge management in complex R \& D projects > , Computers in Industry 48(1) May 2002, P:7. http://textarchive.ru/c2378471.html

[23] Nabhan, Yahya Mohammed (2008). الاساليب الحديثة في التعليم والتعلم > Dar Al Yazouri, Amman. https: / / www.neelwafurat.com/itempage.aspx?id=lbb162815-125410\&search=book

[24] Kafi, Mustafa Yousef (2009) . التعليم الالكتروني والاقتصاد المعرفي> Raslan Foundation for Printing, Publishing and Distribution Damascus, Syria. https://www.overdrive.com/publishers/

[25] Al-Khalidi, Marwan Abdul Redha (2017) > تحليل كتب الفيزياء للمرحلة الاعدادية في ضوء مهارات > الاقتصاد المعرفي ومدى المام المدرسين بها . Unpublished Master Thesis, an unpublished master thesis, University of Qadisiyah, College of Education.

[26] Al-qutha, Ali (2004). اقتصاد المعرفة > Yarmouk Research Journal for Humanities, vol. 31, no. 58.(wep pdf). http: / / journals.yu.edu.jo/ayhss/Issues/Vol27no32011.pdf

[27] Al-Omari, Saleh Mohammed (2004). تدريس الجغرافية وفق بوابة الاقتصاد المعرفي> Al-Dustour Press, Amman.

[28] Al-Hashemi, Abdulrahman and Fayza Mohammed Al-Azzawi (2009) الاقتصاد المعرفي وتكوين >.1st Floor, Al-Masirah Publishing and Distribution House, Amman, Jordan. http:/ / damascusuniversity.edu.sy/mag/law/images/stories/1-2012/a/591-610.pdf [29] Al-Nimrawi, Ziad Mohammad (2014): تقويم كتاب الرياضيات للصف الثاني ثانوي العلمي في الاردن في / > ضوء الاقتصاد المعرفي من وجهه نظر معلميه > Published Research, Damascus University Journal, Volume (30), Issue (2). http://www.damascusuniversity.edu.sy/mag/edu/images/stories/2-2014/ar/241272.pdf

[30] Bloom, B. S. (1971): < Handbook on formative and summative evaluation of student learning >. New York. https: / / www.scirp.org/(S(i43dyn45teexjx455qlt3d2q))/ reference/ReferencesPapers.aspx?ReferenceI $\underline{D}=1614141$

[31] Scott, W.A. \& Mchorel. W.,(1969).< introduction to psychological Research >, New York, Wiley. https: / / www.amazon.com/Introduction-Psychological-Research-William Scott/dp/047176857X

[32] Al-Dulaimi, Ihsan Aliwi (2015). الاختبارات والمقاييس التربوية والنفسية> > Bab Al-Muadam Press, Baghdad.

عبد، هاله محمد. (2019). تقويم محتوى كتاب الحاسوب للصف الثاني متوسط في ضوء مهارات الاقتصاد المعرفي. doi.org/10.36371/port.2018.02.3.10 J Journal Port Science Research 